\title{
Construção de competências, sustentabilidade e competitividade no Sistema Produtivo e Inovativo do Carnaval Carioca
}

\author{
Marcelo Pessoa de Matos \\ Jorge Nogueira de Paiva Britto*
}

\begin{abstract}
RESUMO
A partir do referencial conceitual e analítico de Arranjos e Sistema Produtivos e Inovativos Locais - ASPILs, este artigo analisa as diversas atividades e agentes associados ao carnaval carioca. O sistema produtivo e inovativo local do carnaval é constituído por diversos tipos de agentes produtivos - alguns com uma clara orientação econômica, outros caracterizados como entidades sem fins lucrativos - bem como uma ampla rede de instituições voltadas para ensino e capacitação, representação e apoio e promoção. Juntos constituem um sistema com fortes interconexões e complementaridades que convergem para a organização do produto denominado "a experiência do carnaval". A partir de uma perspectiva sistêmica, busca-se analisar como estes agentes interagem, como são gerados, difundidos e usados os conhecimentos e quais são os determinantes da atratividade e sustentabilidade desta manifestação cultural. Os esforços direcionados à inovação e aqueles direcionados à preservação de características desta manifestação cultural se complementam num processo dinâmico de evolução. Enquanto que as pequenas inovações que ocorrem a cada ano, caracterizadas como inovações "incrementais", estimulam o renovado interesse do público pelo desfile, as inovações de grande impacto, caracterizadas como "radicais", constituem um potencial atrativo de cada desfile e impulsionam o processo de transformação desta manifestação. Diversos "subsistemas" e as capacitações técnicas/produtivas, organizacionais e artísticas associadas se articulam para a produção de uma manifestação única, impossível de ser reproduzida em outro ambiente. Este estoque de conhecimentos se encontra fortemente enraizado no território local e sua preservação e difusão é fortemente determinada pelos processos interativos e, maiormente, informais de aprendizagem.
\end{abstract}

Palavras-Chave: Arranjos e Sistemas Produtivos e Inovativos Locais; Atividades de base cultural; Inovação e preservação; Atratividade e sustentabilidade

\begin{abstract}
Based on the conceptual and analytical framework of Local Innovation and Production Systems and Arrangements, this study analyzes the various activities and actors associated with Rio's Carnival. The local innovation and production system of carnival consists of various types of productive agents some with a clear economic orientation and others characterized as nonprofit organizations - as well as

\footnotetext{
* Marcelo Pessoa de Matos: Professor do Instituto de Economia da UFRJ. Pesquisador da RedeSist. marcelomatos@ie.ufrj.br

Jorge Nogueira de Paiva Britto: Professor da Faculdade de Economia da UFF. Pesquisador da RedeSist. jbrit@terra.com.br
} 
a wide network of institutions dedicated to education and training, representation, support and promotion. Together they constitute a system with strong interconnections and complementarities that converge to the organization of the product called "the experience of carnival". Based on a systemic perspective we seek to analyze how these agents interact, how knowledge is generated, diffused and used and what are the determinants of attractiveness and sustainability of this cultural event. Efforts aimed at innovation and those directed to the preservation of some features of this cultural event complement each other in a dynamic process of evolution. While small innovations that occur each year, characterized as "incremental" innovations, stimulate the renewed public interest in the parade, the innovations of great impact, characterized as "radical", are main drivers of the transformation of this event. Various "subsystems" and the capabilities at the technical/productive, organizational and artistic levels are articulated for the production of a unique manifestation, making it impossible to be reproduced in another environment. This stock of critical knowledge is deeply rooted in the local territory and its preservation and diffusion is strongly determined by the interactive and mostly informal learning processes.

Keywords: Local Innovation and Production Systems and Arrangements; Cultural activities; Innovation and preservation; Attractiveness and sustainability. 


\section{Introdução}

A produção de intangíveis passa a ganhar grande destaque com a introdução do paradigma tecnológico baseado em tecnologias da informação e comunicação - TICs. Este novo paradigma inaugura o que é denominado por muitos como a "era da informação" ou "era do conhecimento". Em todas as esferas da economia aspectos intangíveis, com destaque para o conhecimento, contribuem crescentemente para a majoração do valor de bens e serviços. Atividades de base cultural ou criativa colocam-se, cada vez mais, como elementos de destaque na economia mundial. Estas atividades são consideradas como algumas das mais criativas e intensivas em inovação da economia mundial e passam a ser reconhecidas como estratégicas para o desenvolvimento econômico e social, dado seu potencial de geração de emprego e renda e seus efeitos indutores sobre diversas outras atividades econômicas.

Segundo estudo realizado pela Unesco (2000), a indústria cultural era responsável, no início da década de 1990, por cerca de 4\% do PIB dos países da OCDE, enquanto que esta participação variava entre 1 a 3\% nos países menos desenvolvidos. Diversas estimativas sugerem uma participação de atividades culturais na composição do PIB brasileiro que varia de $1 \%$ até 3\% (Getino, 2001). O Estado e, especialmente, a cidade do Rio de Janeiro têm um peso especial na produção cultural brasileira. Um estudo recente (FAPERJ; COPPE/UFRJ, 2002) estima que no Estado do Rio de Janeiro a cultura responda por cerca de 3,8\% do PIB local. Em termos comparativos ao valor da produção cultural no Brasil em 1999, o Estado responderia por $52 \%$ deste total.

A cidade do Rio de Janeiro tem se destacado pela produção de grandes eventos e espetáculos, com significativo impacto sobre a economia local. Tal impacto se mostra especialmente expressivo na indústria do turismo, com os hotéis apresentando taxas de ocupação próximas de $100 \%$ e com um expressivo aumento de chegadas de turistas. O réveillon carioca se tornou um evento internacionalmente conhecido e tem atraído a cada ano um número maior de pessoas. As diversas edições do Rock in Rio confirmam a vocação carioca para a realização de grandes eventos musicais. Por fim, destaca-se o carnaval carioca, tido como o maior espetáculo da terra.

O aprofundamento de estudos para além da indústria de transformação leva, antes de tudo, à necessidade de uma melhor conceituação das atividades de serviços. As diversas tentativas de conceituá-las, assim como as classificações e taxonomias propostas, têm tido grande dificuldade para dar conta, de um lado, de sua singularidade frente aos demais setores 
e, de outro, da elevada heterogeneidade interna do setor. Tendo em vista estudos recentes de tais atividades com base numa perspectiva evolucionária, observa-se que os empreendimentos inovam, mas com características e graus de intensidade bastante variados. Em geral, o foco na análise da inovação em serviços recai sobre a contribuição destes para a inovação em elementos tangíveis, desconsiderando que a inovação em intangíveis pode representar um significativo elemento de competitividade e, portanto, um fim em si.

Este estudo busca caracterizar as atividades relacionadas ao carnaval carioca como um sistema produtivo e inovativo local, em cujo centro se encontram agentes culturais - as escolas de samba. Portanto, seu objetivo é o entendimento da forma de estruturação e funcionamento deste sistema, identificando como esta manifestação cultural se articula com a economia local e analisando os condicionantes de sua atratividade, sustentabilidade e desenvolvimento.

Tal esforço é baseado no referencial metodológico e analítico de Arranjos e Sistemas Produtivos e Inovativos Locais - ASPILs. Este representa um importante referencial de análise para os mais variados setores produtivos, uma vez que tal perspectiva permite uma compreensão sistêmica da atividade produtiva e inovativa dos agentes que compartilham um mesmo contexto social, cultural e institucional. Sugere-se que este referencial representa uma valiosa ferramenta de análise para o estudo de atividades de base cultural.

$\mathrm{Na}$ próxima seção, apresenta-se o referencial conceitual de sistemas e arranjos produtivos e inovativos locais e se empreende uma discussão acerca da definição e do recorte do objeto de análise. A seção seguinte apresenta as atividades e os agentes que constituem este sistema. A próxima seção analisa os fatores que determinam a atratividade e sustentabilidade do sistema. A última seção apresenta as principais conclusões do estudo.

\section{Arranjos Produtivos Locais e atividades criativas/culturais}

O referencial de Arranjos e Sistemas Produtivos e Inovativos Locais - ASPILs tem como ponto central de sua análise o papel desempenhado pela inovação e pelo aprendizado como fatores dinâmicos para a competitividade. Sistemas e arranjos produtivos e inovativos locais são definidos como o conjunto de atores econômicos, políticos e sociais, localizados em um mesmo território, desenvolvendo atividades econômicas correlatas e que apresentam vínculos expressivos de produção, interação, cooperação e aprendizagem. SPILs geralmente incluem empresas - produtoras de bens e serviços finais, fornecedoras de equipamentos e 
outros insumos, prestadoras de serviços, comercializadoras etc. -, clientes, cooperativas, associações e representações e organizações voltadas à formação e treinamento de recursos humanos, informação, pesquisa, desenvolvimento e engenharia, promoção e financiamento (RedeSist, 2005).

Para a análise do caso específico do carnaval carioca dentro de uma perspectiva de um sistema produtivo e inovativo local, cabe contemplar as características das atividades envolvidas, que podem implicar uma forma específica de analisá-las. Trata-se de um conjunto de serviços, em cujo centro está um tipo de atividade cultural que é complementada por uma série de atividades, as quais podem ser vistas como serviços auxiliares à experiência do carnaval.

Miles (1994) sugere a definição do setor de serviços como aquele que "transforma o estado de bens materiais, as próprias pessoas e elementos simbólicos (com destaque para a informação)". Observa-se uma grande variedade entre as atividades agrupadas dentro do conjunto serviços, tornando difícil apontar características específicas que se apliquem a todos os setores englobados pelo termo. Argumenta-se que esta diversidade (que se faz evidente na característica dos produtos, na organização da firma, na estrutura da indústria, na lógica competitiva etc.) se revela muito maior do que no caso de atividades manufatureiras. Miles (ibid) propõe uma classificação de tipos de serviços de acordo com o seu mercado-alvo e de acordo com os processos produtivos, com implicações distintas sobre a atividade produtiva e inovativa. ${ }^{1}$ Em termos dos possíveis mercados, enumeram-se os serviços direcionados ao consumidor final aqueles direcionados a produtores de outros bens ou serviços e aqueles relacionados a serviços considerados de caráter público. Tendo em vista o processo produtivo, podem-se identificar os serviços que "transformam" o estado de bens tangíveis, pessoas ou a informação.

Uma categorização que tem se difundido nos últimos anos surge a partir da observação da crescente participação de atividades econômicas cujo principal fator gerador de valor reside na criatividade, materializada em produtos. Muitos autores têm direcionado seus esforços de pesquisa, balizando sua investigação pelo conceito de "indústrias criativas". Outras terminologias associadas que emergem recentemente são "economia do conhecimento" e "economia criativa", muitas vezes se referindo a transformações da

\footnotetext{
${ }^{1}$ Destaca-se esta classificação dentre as diversas classificações propostas, que tomam como referência, com ênfases distintas, características dos processos produtivos, tipos de consumidores e/ou funções dos serviços no sistema econômico. Uma extensa resenha destas classificações pode ser encontrada em Meirelles (2003).
} 
economia como um todo, outras vezes enfocando o conjunto de atividades tidas como "criativas" ou culturais.

A definição de "indústrias criativas", com maior destaque no debate recente, se revela a menos precisa e a mais marcada por aspectos ideológicos e políticos. ${ }^{2}$ Descreve-se este conjunto de atividades como aquelas que derivam da criatividade e habilidade individual e que geram fluxos econômicos pela exploração de direitos de propriedade intelectual. Esta definição se mostra tão vaga quanto abrangente, permitindo que se incluam os mais diversos setores de atividade econômica como os relacionados às novas tecnologias de informação e comunicação. Em tese, como apresentado por Bilton e Leary (2002), qualquer setor industrial se vale de algum grau de criatividade individual, habilidade e talento. Da mesma forma, a crescente variedade de produtos dos diversos setores incorpora algum tipo de componente intelectual, na forma de patentes, elementos de design ou outras propriedades intangíveis e simbólicas que tornam um produto único. Perde-se, assim, o caráter específico de atividades econômicas de base cultural e artística, que passam, então, a ser abarcadas pelo guarda-chuva das indústrias criativas, impossibilitando qualquer corte analítico minimamente preciso.

Propõe-se, neste estudo, o emprego do referencial de "atividades de base cultural". Uma aproximação do que seriam atividades de base cultural é proposta por O’Connor (1999) e por Bilton e Leary (2002). Estes autores sugerem que atividades culturais sejam aquelas que lidam essencialmente com bens simbólicos - bens cujo valor econômico (caso haja algum) deriva de seu valor cultural intrínseco, que, por definição, é subjetivo. Reconhece-se que esta definição é, também, um tanto quanto imprecisa. A distinção entre atividades que lidam, primordialmente, com bens simbólicos e aquelas que lidam com bens "funcionais" é mais uma distinção de grau de que de tipo (Bilton e Leary, 2002). Como dito acima, à medida que a marca e outros aspectos similares de um produto ganham maior peso na decisão de consumo, maior ênfase é dada a aspectos simbólicos não funcionais (O’Connor, 1999). Neste caso, aspectos simbólicos e culturais podem majorar o valor de um bem, enquanto que, no caso de atividades de base cultural, o valor cultural é determinante (praticamente único) do possível valor econômico. Além disso, no caso de atividades de base cultural, os aspectos simbólicos são específicos a cada grupo social com seu conjunto de crenças, valores e códigos.

\footnotetext{
${ }^{2}$ Não por acaso, o termo Creative Industries surge em 1997 em um documento do recém-criado Departamento de Cultura, Mídia e Esporte (Department of Culture, Media and Sport - DCMS) do então empossado governo Tony Blair no Reino Unido (Pratt, 2005). São enumerados os setores: publicidade; arquitetura; antiquários; artesanato; design; estilismo; filmes; música; televisão e rádio; artes performáticas; publicidade; software e, especificamente, softwares interativos de entretenimento (DCMS, 1998). Como apontado por O'Connor (1999) e Flew (2002), a listagem do grupo de indústrias contém um caráter bastante ad hoc e pragmático, dadas as atividades que passam a ser foco prioritário de políticas neste país.
} 
Em termos gerais, a cultura influencia os indivíduos que compartilham códigos comuns, crenças e valores em uma sociedade (Hollanda, 2002) e, em termos específicos, é o elemento-chave que caracteriza um grupo de atividades produtivas - motivada ou não por objetivos econômicos. "Indústrias culturais" são geralmente definidas como as atividades culturais que são conduzidas, mesmo que apenas em parte, por uma lógica econômica. As seguintes indústrias são geralmente incluídas neste grupo: música, cinema, televisão, radiodifusão, livros, revistas e jornais, publicidade, design, artes cênicas, artes visuais e artesanato. Somando-se a essas atividades as atividades culturais que podem gerar, mesmo que indiretamente, impactos econômicos, temos o conjunto de "atividades de base cultural" ou, como o usado no restante do texto, "atividades culturais".

Considerar até mesmo atividades não orientadas por objetivos econômicos mostra-se importante para a análise econômica. Como dito, o presente estudo centra-se em um conjunto de serviços, em cujo centro está um tipo de atividade cultural, que não tem fins lucrativos e que é complementada por uma variedade de serviços "auxiliar" para a experiência do carnaval. Além disso, este sistema abrange atividades econômicas da indústria de transformação, bem como diversas organizações não econômicas.

\section{O Sistema Produtivo do Carnaval}

Embora o foco deste estudo esteja sobre os agentes culturais (as escolas de samba), busca-se contemplar a multiplicidade de agentes e relações envolvidas que configuram um sistema produtivo e inovativo local. As escolas de samba são entidades culturais sem fins lucrativos, cuja principal atividade consiste na realização do desfile durante o carnaval. De um total de aproximadamente 80 escolas de samba na área metropolitana do Rio de Janeiro, 36 realizam seu desfile no sambódromo (as agremiações do grupo especial e dos grupos A e B). As demais escolas de samba realizam seus desfiles atualmente na Avenida Intendente Magalhães na Zona Norte da Cidade.

Mais do que uma festividade, o desfile das escolas de samba constitui uma competição entre as agremiações. As escolas de samba se encontram divididas em seis grupos: o grupo especial e os grupos A, B, C, D e E. Um corpo de jurados avalia a performance das escolas de samba e atribui notas aos diversos quesitos avaliados. A soma destas notas indica, então, a escola de samba campeã do desfile em cada grupo. A cada ano as escolas de melhor 
colocação nos seus grupos ascendem para o grupo superior e as escolas de samba de pior colocação descem para o grupo inferior.

O número de participantes no desfile varia, de acordo com o grupo, de 2000 a 4000. Da mesma forma, o número de alegorias varia entre quatro e oito. A ala da bateria é composta por 150 a 300 ritmistas. A duração do desfile varia entre 40 e 80 minutos. Os desfiles ocorrem ao longo das noites de sexta-feira (Escolas de samba mirins), sábado (grupo A), domingo e segunda-feira (grupo especial) e terça-feira (grupo B) antes da quarta-feira de cinzas.

Uma parte dos participantes no desfile não integra a organização. Eles adquirem o direito de participar do desfile ao comprarem as fantasias da escola. A cada ano cada escola de samba adota um enredo novo, fazendo menção a fatos históricos, lugares, pessoas, culturas etc. A criação dos elementos visuais (fantasias, adereços e alegorias), dos elementos musicais (samba-enredo) e performáticos é orientada pelo enredo adotado, de forma que nenhum desses elementos é usado por mais de que um carnaval.

A produção, ano após ano, deste carnaval movimenta um complexo sistema produtivo, envolvendo diferentes cadeias produtivas e profissionais de diversas áreas de conhecimento. O entendimento da dinâmica de produção do desfile constitui a base para o entendimento dos desafios que esta indústria enfrenta.

O sistema produtivo e inovativo do carnaval carioca é constituído por uma ampla gama de agentes econômicos, sociais e culturais. Dentre as atividades produtivas, o sistema engloba uma gama variada de atividades industriais e de serviços. A Figura 1, abaixo, apresenta uma esquematização dos componentes do sistema. Identificam-se cinco conjuntos principais de agentes e atividades neste sistema: um relacionado à coordenação do sistema; um relacionado à produção/preparação do espetáculo; um relacionado à organização e realização do desfile, bem como à infraestrutura de turismo; o sistema de educação e C\&T e outros segmentos das indústrias culturais. As escolas de samba estão colocadas no centro deste sistema, como principal agente produtivo. Da mesma forma, o produto final deste sistema, o desfile, encontra-se em posição central, dado que as diversas atividades do sistema convergem para a consecução deste. As setas e traços entre os agentes representam fluxos e relações econômicas entre os agentes, que são descritos na sequência. 
Figura 1. Esquematização do sistema produtivo e inovativo do carnaval carioca

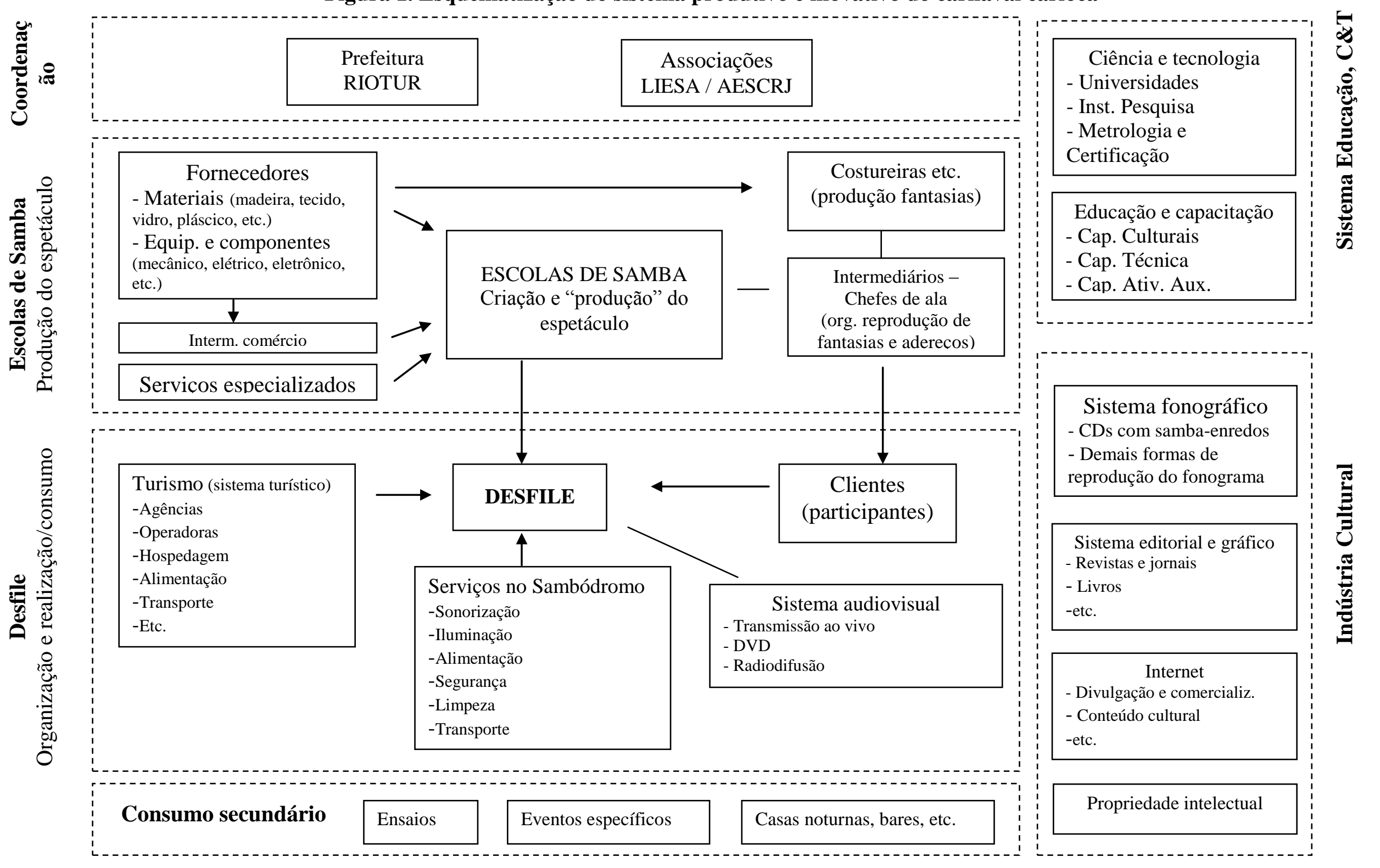


Fonte: Elaboração própria, baseado em Matos (2007) e Prestes Filho (2009). 


\subsection{O processo produtivo}

Embora o principal atrativo (ou serviço) oferecido pelas escolas de samba ocorra apenas durante o carnaval, trata-se de uma indústria atuante durante todo o ano, com a preparação gradual do desfile, a realização de apresentações e eventos. A "produção do desfile" pode ser desmembrada em quatro "subsistemas" que convergem para o produto final: (i) a produção de fantasias e adereços; (ii) a produção dos carros alegóricos; (iii) a criação e preparação dos elementos musicais (samba-enredo e bateria) e (iv) a criação e preparação dos elementos performáticos (coreografias etc.).

As atividades de uma escola de samba para a preparação do seu desfile seguem uma ordem cronológica e são distribuídas ao longo do ano. No mês posterior ao desfile anterior são iniciados os preparativos para o próximo carnaval. Num primeiro momento, se dá a concepção artística do próximo desfile. O ponto inicial é a definição e contratação do carnavalesco ${ }^{3}$ responsável pela criação do próximo desfile e pela coordenação dos diversos "subsistemas" descritos acima. Este, juntamente com o corpo de diretores, cria o enredo (o tema do desfile) e sua sinopse (descrição do enredo e a forma de este ser desenvolvido no desfile) e elabora uma proposta preliminar de orçamento.

O carnavalesco forma a sua equipe de trabalho, constituída por profissionais que possuem especialização como ferreiros, marceneiros, carpinteiros, escultores, eletricistas, iluminadores, desenhistas, cenógrafos, figurinistas, aderecistas, costureiras, bordadeiras, vidraceiros, pintores, ceramistas e decoradores. Estes profissionais são, normalmente, contratados por indicação dos carnavalescos (Araújo, 2002).

Ao longo de maio e junho são elaborados os protótipos de fantasias (produzidos por costureiras do barracão) e projetados os carros alegóricos. O desenho das alegorias envolve uma planta baixa e uma planta artística, sendo, geralmente, contratados três a quatro arquitetos para a realização desta etapa. $^{4}$

Durante o mesmo período, parte da concepção artística do desfile é atribuída a outros agentes. O enredo é apresentado aos compositores ligados à escola, que passam a compor as músicas que concorrerão a samba-enredo da escola. Verifica-se um número médio de vinte a quarenta sambas inscritos para a disputa. Em agremiações de grande prestígio este número chega a atingir sessenta

\footnotetext{
${ }^{3} \mathrm{O}$ carnavalesco é o principal agente criativo do espetáculo, cabendo a ele a concepção do desfile em todos os seus detalhes e a coordenação das equipes responsáveis pelas diversas etapas de produção de fantasias e carros alegóricos.

${ }^{4}$ Tanto para o desenho das alegorias como também para a elaboração dos projetos das fantasias, destaca-se o crescente emprego de programas de computador desenhados para este fim, como processos CAD.
} 
inscrições (Pegado, 2005). ${ }^{5}$ Normalmente as composições são gravadas em fitas ou compactos, que são entregues à diretoria da escola para que esta pré-selecione os sambas a serem apresentados para disputa na quadra. Os compositores recebem pelos direitos autorais de suas composições e ganham prêmios em dinheiro a cada nova fase eliminatória nos concursos internos para a escolha do samba. ${ }^{6}$ A escolha do samba ocorre, normalmente, por volta do mês de outubro e é seguida por sua gravação, para que o álbum com os samba-enredos de todas as escolas esteja disponível para comercialização no período do Natal. Paralelamente, ocorre durante o segundo semestre a preparação ou ensaio da bateria, principalmente durante as festividades abertas ao público promovidas nas quadras.

Da mesma forma, a concepção artística ligada a elementos performáticos é atribuída a coreógrafos, dançarinos e outros artistas ligados à escola ou que são contratados para este fim. Grupos de integrantes que realizarão performances durante o desfile são formados e as coreografias ensaiadas a partir do último trimestre do ano. Coreografias de alas, comissão de frente e de integrantes nas alegorias são guardadas em sigilo, dado que constituem um elemento importante de novidade e de estabelecimento de diferencial com relação às demais escolas de samba.

Em agosto dá-se início ao processo de confecção de fantasias. Os protótipos de fantasias, concebidos pelo carnavalesco e confeccionados por costureiras das próprias escolas de samba, são entregues aos chefes de ala. Estes contratam costureiras e aderecistas para a confecção das fantasias e adereços $\mathrm{da}(\mathrm{s})$ ala(s) sob sua responsabilidade. Os chefes de ala também assumem a tarefa de comercialização das fantasias, obtendo, usualmente, uma margem de $100 \%$ sobre o custo de produção das fantasias (Lessa e Aguinaga, 2002). O preço de venda costuma variar entre 120 e 250 reais, podendo chegar, em alguns casos, a cerca de 600 reais. As fantasias de alas sob responsabilidade da escola (comissão de frente, bateria, baianas e alas da comunidade) são produzidas no próprio barracão e doadas aos integrantes. A confecção de fantasias de destaques e dos casais de porta-bandeira e mestresala é encomendada a costureiras especializadas.

Quanto aos carros alegóricos, a primeira etapa envolve o desmonte dos carros alegóricos, selecionando-se o material a ser reaproveitado ao longo dos meses de março a maio. Em julho inicia-se o processo de montagem das novas alegorias, que se estende até poucos dias antes do desfile. Esta montagem segue uma sequência de etapas, envolvendo diferentes profissionais, sua maioria sendo contratada em regime temporário. A partir de dezembro verifica-se um maior número de pessoas nos

\footnotetext{
${ }^{5}$ Apesar de as escolas possuírem suas alas de compositores, a maioria não impede que compositores não ligados à agremiação participem da disputa, o que reflete mais uma face do crescente processo de profissionalização das atividades relacionadas à produção do desfile.

${ }^{6}$ Os intérpretes e cantores se beneficiam com a disputa. Muitos compositores pagam estes músicos para que gravem seus sambas em um estúdio e/ou o defendam durante a disputa nas quadras.
} 
barracões, sendo que o pico do trabalho ocorre nos meses de janeiro e fevereiro, com cerca de 300 pessoas ocupadas. As diversas etapas envolvem: instalação de ferragens; montagem de carpintaria; criação das esculturas; pintura; adereçamento; instalações elétricas e de efeitos especiais; mecânica.

Um marco da progressiva melhoria das condições de produção do carnaval é a inauguração da "Cidade do Samba", que ocorreu em setembro de 2005. Trata-se de um complexo de 70 mil metros quadrados onde se encontram 14 modernos barracões - ou como são formalmente chamadas "fábricas de carnaval" - ocupadas pelas escolas de samba do grupo especial. ${ }^{7}$

Cada "fábrica" possui uma área total de cerca de 7000 metros quadrados: o térreo, com um pátio interno onde são produzidas as alegorias, com uma área de 2700 metros quadrados e um vão de 12 metros de altura; três pavimentos intermediários de 600 metros quadrados, onde se encontram butiques, almoxarifados, cozinhas, refeitórios, sanitários, setores administrativos e de criação; e um pavimento superior de cerca de 2700 metros quadrados, com ateliês de costura, chapelaria, adereçaria, oficinas de escultura em isopor e modelagem em fibra de vidro.

Para as escolas de samba do grupo especial, esta infraestrutura rompe com as condições até então pouco adequadas de produção do espetáculo, que era realizado nos galpões adaptados de forma improvisada e com um espaço interno inadequado às dimensões das alegorias. O pátio interno em cada “fábrica de carnaval" permite a construção simultânea de até 12 alegorias em seu tamanho final (Liesa, 2007).

O planejamento da produção tem sido marcado crescentemente pelo profissionalismo, como reflexo da crescente concorrência entre as escolas e a transformação no desfile em um grande espetáculo. De uma atividade gerida de forma amadora por um pequeno número de pessoas, as escolas de samba assumem gradativamente características de empresas, com a incorporação de profissionais especializados em diversas áreas, como marketing, contabilidade, RH, advocacia, comunicação etc. Como apontado em entrevista durante a pesquisa de campo, a profissionalização da produção do desfile nas escolas de samba tem possibilitado uma redução de custos organizacionais e de produção, bem como a captação de novas fontes de recursos e o melhor planejamento e organização das etapas

\footnotetext{
${ }^{7}$ A Cidade do Samba ocupa um terreno de 70 mil metros quadrados, na Zona Portuária (Gamboa), área que pertencia à Rede Ferroviária e foi comprada pela Prefeitura. O custo total da obra foi de cerca de R\$ 74 milhões. O complexo conta ainda com uma praça central com duas lonas - uma para espetáculos e outra para exposições. A ocupação de uma "fábrica" por uma escola de samba é garantida apenas por um ano, dado que as escolas que caem a cada ano para o grupo A têm que desocupar as "fábricas", dando lugar as escolas que ascendem para o grupo especial (Liesa, 2007).

A "Cidade do Samba" oferece às escolas de samba uma possibilidade adicional de oferecer atrativos fora do período do carnaval. Desde setembro de 2006 o complexo está aberto à visitação pública com uma gama variada de oferta de atrativos, como demonstrações em oficinas de dança, escultura em isopor, confecção de fantasias e afinação de instrumentos de percussão, apresentação de intérpretes e integrantes das escolas, como passistas, ritmistas, casais de mestres-salas e portabandeiras, baianas e destaques (Liesa, 2007).
} 
produtivas. ${ }^{8}$ Recursos advindos de patrocínios se tornam cada vez mais importantes, dada a competição entre as escolas que induz a um contínuo aumento do custo total de produção. Uma escola de samba do grupo especial, por exemplo, tem um custo de aproximadamente R $\$ 12$ milhões, sendo que os recursos referentes à participação nas receitas do desfile e subvenções públicas totalizam cerca de $\mathrm{R} \$ 6$ milhões.

Um reflexo disto pode ser observado na escolha e elaboração dos enredos nos últimos anos. Observa-se uma tendência de escolha de enredos que exaltam personalidades, organizações ou lugares que justifiquem ou possibilitem a obtenção de patrocínio por parte de tais pessoas, organizações ou poder público de tais localidades.

\subsection{Fornecedores}

Os insumos para a produção das fantasias, adereços e alegorias podem ser divididos em três grandes grupos. Um grupo é constituído por matérias-primas "especializadas" como tecidos, plumas e uma variedade de itens que conferem cor, brilho e textura às fantasias e adereços. Um segundo grupo é constituído por insumos básicos como madeira, ferragens, isopor etc. Um terceiro grupo seria constituído por máquinas e equipamentos.

No caso dos dois últimos grupos, as escolas de samba os adquirem, maiormente, junto a uma ampla rede de estabelecimentos comerciais. Estes insumos possuem pouca especificação em termos de sua aplicação na produção do desfile. O que lhes confere valor artístico é a sua utilização e/ou transformação criativa. Portanto, não existe grande especialização por parte dos fornecedores e intermediários, sendo estes insumos adquiridos junto a uma grande variedade de fornecedores e intermediários em toda a área do Grande Rio.

Os insumos caracterizados como "especializados" (franjas, fitas, fitilhos, metalizados, furtacores, plumas e pequenos enfeites como vidrilhos e miçangas etc.) possuem, inerente a suas características físicas, elementos estéticos que conferem "valor" ao produto final. Cada item específico é utilizado em uma quantidade relativamente pequena, de forma que se torna pouco funcional para cada escola de samba direcionar sua demanda aos produtores de tais bens. A demanda das agremiações é direcionada para um grupo pequeno de empreendimentos comerciais especializados em produtos para $\mathrm{o}$

\footnotetext{
${ }^{8}$ Mas a realização das diversas etapas se encontra condicionada à liberação de recursos (subvenções e adiantamentos da participação nos recursos relativos a bilheteria e direitos de transmissão) para o pagamento dos diversos profissionais e para a aquisição dos insumos, inviabilizando o estabelecimento de um cronograma rígido de produção.
} 
carnaval. ${ }^{9}$ Estes centralizam a demanda junto aos produtores de diferentes partes do Brasil e do exterior em quantidades maiores, oferecendo às escolas de samba uma gama variada de produtos.

Outro fator determinante para estes empreendimentos centralizarem a demanda das escolas de samba está relacionado às condições de pagamento. As escolas de samba dependem, em grande parte, da subvenção concedida pelo poder público e dos recursos referentes a bilheteria e direitos de transmissão do desfile, que são adiantados para as escolas de samba. Mas grande parte destes recursos é apropriada pelas agremiações apenas durante o último triênio do ano. Todavia, as escolas de samba já iniciam suas atividades no mês de abril, como descrito acima. Para a aquisição dos insumos necessários para que as escolas de samba possam cumprir seu cronograma de preparação para o carnaval, estabeleceu-se um sistema de pagamento baseado em cartas de crédito informais, centrado em relações de confiança entre as partes envolvidas. As agremiações adquirem os insumos mediante a emissão de uma carta de crédito que reconhece sua dívida e sem a definição de uma data exata para que a dívida seja saldada. Não por acaso, durante a pesquisa de campo a flexibilidade nas condições de pagamento foi apontada pela totalidade das agremiações como a principal razão para a compra junto a tais lojas.

Todavia, tal estrutura contribui para a majoração dos custos de produção do carnaval através de dois mecanismos. Em primeiro lugar, a disponibilidade de um novo insumo em uma quantidade reduzida pode levar a uma disputa entre as escolas de samba, possibilitando ao comerciante majorar o preço do mesmo. Um segundo mecanismo está associado à dinâmica temporal de produção do desfile. Uma vez que os protótipos das fantasias são elaborados, a agremiação se encontra comprometida com a aquisição futura de uma certa quantidade de insumos. Dada a especificidade de muitos destes, a organização possui pouca flexibilidade para obter ou negociar melhores preços. Porém entrevistas junto às escolas de samba indicam ser esta uma preocupação apenas secundária para as agremiações, dada a primazia conferida à "qualidade" e beleza do produto final a ser apresentado no desfile.

No caso de muitos produtos, não existe uma produção local significativa e a demanda, principalmente através dos estabelecimentos comerciais citados acima, se desloca para outras cidades do estado e, principalmente, para o Estado de São Paulo. ${ }^{10}$ Isto se aplica, especialmente, a produtos da indústria têxtil e de máquinas e geradores para carros alegóricos, bem como plástico, borracha, papéis, tinta e pigmentos. No caso da indústria de malharia e de lycra existe uma significativa produção local. Destaca-se a produção de malhas por uma fábrica localizada em Del Castilho, cujas vendas sofrem um

\footnotetext{
${ }^{9}$ Todos os entrevistados na pesquisa de campo citaram dois ou mais dos seguintes estabelecimentos comerciais: Babado da Folia, Caçula, Casa Pinto e Kirki.

${ }^{10}$ Com o apoio do Sebrae/RJ, empresas do polo de produção de calçados de Belford Roxo fornecerão sandálias para sambistas da escola de samba Porto da Pedra. Tal apoio faz parte do empenho desta instituição de fomentar atividades produtivas relacionadas à cadeia produtiva do carnaval no Estado do Rio de Janeiro.
} 
incremento de cerca de 30 a $40 \%$ durante os três meses anteriores ao carnaval. No que se refere a produtos como franjas, fitas, fitilhos, metalizados, furta-cores etc., Lessa e Aguinaga (2002) apontam para a existência de seis empresas no Rio de Janeiro e cerca de dez em São Paulo. Alguns produtos, como plumas e pequenos enfeites (vidrilhos, miçangas etc.) têm sido, crescentemente, importados. ${ }^{11}$

\subsection{Atividades relacionadas ao desfile}

Para a realização do desfile das escolas de samba no Sambódromo é mobilizada uma grande variedade de serviços, tais como atividades relacionadas à iluminação, alimentação, cuidados médicos, segurança, limpeza, transporte etc. Estes serviços são providos por empresas públicas, como Rioluz, Comlurb e guarda municipal, e por empresas privadas prestadoras de serviços contratadas ou que firmam contratos de operação dentro do sambódromo. As associações (Liesa - Liga Independente das Escolas de Samba e AESCRJ - Associação das Escolas de Samba da Cidade do Rio de Janeiro) são responsáveis pela contratação de serviços de sonorização e de cronometragem na passarela, além da contratação de cerca de 800 seguranças de pista, concentração e dispersão e de julgadores.

Apenas a Riotur (Secretaria de Turismo da Cidade do Rio de Janeiro) mobiliza cerca de 2000 pessoas para trabalharem durante os desfiles no sambódromo. O número total de pessoas ocupadas durante os desfiles dentro da passarela do samba foi estimado por Lessa e Aguinaga (2002) em torno de 12 mil pessoas.

Outros agentes relacionados ao desfile são seguradoras. Para realização dos desfiles, são contratados, por parte das associações, diversos tipos de seguros, tais como de responsabilidade civil, de acidentes pessoais e no-show. Dados do ano de 1999 apontam para um custo total destes seguros de aproximadamente $\mathrm{R} \$ 59$ mil para um capital segurado de cerca de $\mathrm{R} \$ 6$ milhões (no-show) e $\mathrm{R} \$ 1,5$ milhão (responsabilidade civil). ${ }^{12}$

A exemplo do que ocorre no nível das escolas de samba, empresas são importantes patrocinadoras do evento como um todo. Os recursos advindos de anunciantes e patrocinadores são destinados a cobrir parte dos custos de organização do desfile. Os contratos de patrocínio são firmados, no caso do desfile das escolas de samba do grupo especial, entre as empresas e a Liesa, podendo assumir três formas gerais, não mutuamente excludentes: (i) contratos para a exposição de material publicitário; (ii) contratos para a instalação de stands ou ocupação de camarotes e comercialização de seus produtos; e (iii) contratos de exclusividade na comercialização de certos tipos de produto.

\footnotetext{
${ }^{11}$ Instituto Pereira Passos e Secretaria Especial de Assuntos Estratégicos, 1999

12 Jornal do Comércio 12/02/1999.
} 


\subsection{Audiovisual e indústria musical}

Os diferentes veículos de comunicação exercem um papel importante na evolução do desfile das escolas de samba. O jornal $O$ Mundo Esportivo promoveu o primeiro concurso/competição das escolas de samba em 1932. Posteriormente, outros veículos de mídia impressa e de rádio promoveram e divulgaram os desfiles, contribuindo para difusão e ampliação do prestígio desta manifestação.

Atualmente, a televisão exerce este importante papel. Um agente central no sistema do carnaval é a Rede Globo de Televisão. A cada ano é firmado um novo contrato com a Liesa para a aquisição do direito de transmissão ao vivo do desfile do grupo especial. Como mencionado acima, os recursos advindos do contrato de direito de transmissão se tornaram uma das principais fontes de recursos para as escolas de samba. O valor deste contrato tem crescido ano após ano. Em 2004 este valor foi da ordem de $\mathrm{R} \$ 8,4$ milhões e em 2005 de $\mathrm{R} \$ 8,8$ milhões.

A exemplo do que ocorre com patrocinadores do sambódromo, a emissora estabelece contratos de exclusividade, relativos a certos tipos de produto, com anunciantes. Como exemplo figura o contrato firmado entre a emissora e a marca de cerveja Kaiser, sendo esta marca de cerveja a única anunciada durante a transmissão do evento.

Para a cobertura do desfile de 2005, a emissora mobilizou cerca de 800 profissionais, com 23 repórteres na cobertura do evento, além de narradores e comentaristas. Nesse ano, a cobertura do desfile foi transmitida para 52 países através da Globo Internacional a cerca de 250 milhões de telespectadores (Pegado, 2005).

Dado o comprometimento de recursos para a aquisição dos direitos de transmissão do evento, a emissora investe um esforço significativo na promoção do mesmo. São produzidas propagandas e vinhetas relacionadas ao carnaval e chamadas ao vivo, nas quais integrantes das escolas de samba do grupo especial executam o samba da escola ou relatam fatos relacionados à produção e história do carnaval, sendo estas exibidas desde o mês de dezembro. Adicionalmente, são realizadas chamadas ao vivo e matérias sobre a produção do carnaval que agregam a função de jornalismo informativo e de promoção do evento.

Outra forma de envolvimento da transmissora com o carnaval é a promoção da premiação denominada Estandarte de Ouro, promovida desde 1972 pelo jornal $O$ Globo, parte do Grupo Globo de 
Comunicação, o qual elege e premia a melhor escola de samba dos grupos especial e de acesso, bem como outros integrantes e partes constituintes do desfile. ${ }^{13}$

A Gravadora Escola de Samba Ltda, pertencente à Liesa, realiza a gravação, edição e comercialização do álbum com os sambas de enredo das escolas do grupo especial. A produção em estúdio mobiliza cerca de 50 técnicos, de acordo com informação da Liesa. Até o início dos anos 1990 o álbum atingia uma tiragem de cerca de um milhão de cópias vendidas. Em anos recentes, o número de cópias vendidas tem girado em torno de cem mil, podendo este decréscimo ser atribuído às possibilidades de cópia e difusão dos fonogramas, que surgem com a difusão das tecnologias da informação e comunicação (Pegado, 2005).

\subsection{Infraestrutura de turismo e lazer}

Uma indústria que se beneficia diretamente do carnaval são as atividades relacionadas ao turismo e lazer, como hotéis e pousadas, agências de viagem, operadoras, transportes e aluguel de veículos, bares e restaurantes, casas de espetáculo etc. Muitos hotéis também se envolvem em atividades relacionadas à festividade, tais como bailes de gala, apresentação de grupos musicais e integrantes de escolas de samba, além de intermediarem a venda de fantasias e ingressos para o desfile e oferecerem suporte para transporte dos turistas ao sambódromo.

Segundo dados da Riotur, a cidade recebeu, durante o período de carnaval em 2006, 680 mil turistas nacionais e estrangeiros, gerando uma renda aproximada de US\$ 490 milhões com gastos como transporte, hospedagem, alimentação, passeios e compras. Somente os gastos em bares e restaurantes no período do carnaval são estimados em cerca de US\$ 164 milhões (Mesquita, 2006).

\subsection{Valor movimentado pela economia do carnaval}

A quantificação da dimensão econômica das diversas atividades relacionadas ao carnaval constitui uma difícil tarefa, dada a multiplicidade de atividades e agentes envolvidos, o caráter sazonal de muitas destas atividades e o alto grau de informalidade vigente. A título de exemplo, as diversas estimativas existentes divergem amplamente entre si. A estimativa mais recorrente é aquela que sugere que o carnaval carioca movimenta em torno de R 1 bilhão (Medina, 2002). Adicionalmente, Pegado

\footnotetext{
13 As categorias premiadas pelo Estandarte de Ouro são - referentes ao grupo especial - bateria, puxador, enredo, personalidade, revelação, ala, ala de baianas, passista feminino, passista masculino, comissão-de-frente, porta-bandeira, mestre-sala e - referentes ao grupo especial e ao de acesso - melhor escola e samba-enredo.
} 
(2005) apresenta uma estimativa feita pela Riotur que sugere que o carnaval de 2005 tenha movimentado em torno de $\mathrm{R} \$ 1,3$ bilhão, gerando aproximadamente 30 mil empregos.

Por fim, destaca-se o levantamento feito pela Secretaria de Estado de Trabalho - SETRAB/RJ, referente ao carnaval do ano de 2000. A tabela abaixo apresenta uma estimativa do valor total, remuneração e ocupações (formais e informais) geradas pelas diversas atividades ligadas ao desfile no sambódromo.

Tabela 1. Estimativa de valores movimentados e geração de emprego relacionadas ao carnaval de 2000, sob a ótica dos produtores e beneficiários primários

\begin{tabular}{|c|c|c|c|c|c|c|c|c|}
\hline & \multirow[b]{2}{*}{$\begin{array}{l}\text { Valor Total } \\
\text { (mil R\$) }\end{array}$} & \multirow[b]{2}{*}{$\begin{array}{l}\text { Mão de obra } \\
(\text { mil } R \$)\end{array}$} & \multicolumn{3}{|c|}{ Soma postos-mês } & \multirow{2}{*}{$\begin{array}{l}\text { Tempo médio } \\
\text { ocupação } \\
\text { (meses) }\end{array}$} & \multirow[b]{2}{*}{$\begin{array}{l}\text { Pessoas } \\
\text { mobilizadas }\end{array}$} & \multirow[b]{2}{*}{$\begin{array}{l}\text { Remuneração } \\
\text { Média }(\mathrm{R} \$)\end{array}$} \\
\hline & & & número & $\begin{array}{l}\text { Formais } \\
\%\end{array}$ & $\begin{array}{l}\text { Informais } \\
\%\end{array}$ & & & \\
\hline TOTAL & 416.122 & 180.888 & 264.501 & $46 \%$ & $54 \%$ & 0,6 & 470.289 & 683,88 \\
\hline Transportes & 134.733 & 29.260 & 10.890 & $91 \%$ & $9 \%$ & 0,3 & 32.670 & $2.686,89$ \\
\hline Agências de Viagem & 9.681 & 5.718 & 6.668 & $55 \%$ & $45 \%$ & 2,0 & 3.259 & 857,49 \\
\hline Rede Hoteleira & 73.110 & 24.370 & 42.125 & $59 \%$ & $41 \%$ & 0,3 & 121.110 & 578,51 \\
\hline Rede alimentação & 193.896 & 45.673 & 92.786 & $52 \%$ & $48 \%$ & 0,4 & 252.721 & 492,24 \\
\hline Outros & 57.366 & 13.401 & 8.198 & $96 \%$ & $4 \%$ & 0,9 & 8.743 & $1.634,69$ \\
\hline Sambódromo & 22.981 & 13.701 & 12.826 & $54 \%$ & $46 \%$ & 1,5 & 8.562 & $1.068,22$ \\
\hline Gastos Primários & 15.777 & 8.573 & 7.699 & $49 \%$ & $51 \%$ & 10,0 & 770 & $1.113,55$ \\
\hline Liesa & 5.908 & 4.135 & 3.515 & $16 \%$ & $84 \%$ & 10,0 & 351 & $1.176,39$ \\
\hline Riotur & 8.876 & 4.438 & 4.184 & $76 \%$ & $24 \%$ & 10,0 & 418 & $1.060,71$ \\
\hline PMRJ & 994 & - & - & - & - & - & - & - \\
\hline Cadeia Produtiva & 7.204 & 5.128 & 5.127 & $63 \%$ & $37 \%$ & 0,7 & 7.792 & $1.000,14$ \\
\hline Fornec. Sambódromo & 23.750 & 5.000 & 7.386 & $62 \%$ & $38 \%$ & 0,9 & 8.544 & 676,96 \\
\hline Gastos Primários & 12.500 & 1.250 & 3.235 & $44 \%$ & $56 \%$ & 0,5 & 6.469 & 386,40 \\
\hline Cadeia Produtiva & 11.250 & 3.750 & 4.151 & $76 \%$ & $24 \%$ & 2,0 & 2.076 & 903,40 \\
\hline Ambulantes & 1.200 & 533 & 2.501 & $4 \%$ & $96 \%$ & 0,2 & 10.158 & 213,25 \\
\hline Gastos Primários & 800 & 400 & 2.353 & $0 \%$ & $100 \%$ & 0,2 & 10.084 & 170,00 \\
\hline Cadeia Produtiva & 400 & 133 & 148 & $76 \%$ & $24 \%$ & 2,0 & 74 & 900,90 \\
\hline Escolas Samba - Grupo Especial & 74.515 & 29.378 & 48.880 & $27 \%$ & $73 \%$ & 3,0 & 16.099 & 601,02 \\
\hline Gastos Primários & 46.532 & 21.178 & 36.321 & $17 \%$ & $83 \%$ & 3,4 & 10.541 & 583,09 \\
\hline desfile & 233 & 233 & 620 & - & $100 \%$ & 0,2 & 2.659 & 375,81 \\
\hline alegorias & 20.439 & 8.176 & 9.139 & $8 \%$ & $92 \%$ & 6,0 & 1.523 & 894,63 \\
\hline fantasias & 16.100 & 9.660 & 20.905 & $8 \%$ & $92 \%$ & 4,0 & 5.226 & 462,09 \\
\hline samba-enredo & 1.932 & 1.739 & 2.282 & $65 \%$ & $35 \%$ & 4,0 & 571 & 762,05 \\
\hline ensaios/shows & 4.571 & 1.371 & 3.374 & $65 \%$ & $35 \%$ & 6,0 & 562 & 406,34 \\
\hline divulgação & 3.257 & 326 & 158 & $76 \%$ & $24 \%$ & 1,0 & 158 & $2.063,29$ \\
\hline Cadeia Produtiva & 27.983 & 8.199 & 12.559 & $58 \%$ & $42 \%$ & 2,3 & 5.557 & 652,87 \\
\hline $\begin{array}{l}\text { Escolas de Samba - Grupos } \\
\text { Acesso }\end{array}$ & 24.950 & 13.453 & 29.576 & $8 \%$ & $92 \%$ & 3,5 & 8.423 & 454,87 \\
\hline Gastos Primários & 21.700 & 12.370 & 28.403 & $6 \%$ & $94 \%$ & 3,6 & 7.823 & 435,52 \\
\hline Escolas & 6.500 & 3.250 & 8.667 & - & $100 \%$ & 3,0 & 2.889 & 374,99 \\
\hline Fantasias & 15.200 & 9.120 & 19.737 & $8 \%$ & $92 \%$ & 4,0 & 4.934 & 462,08 \\
\hline Cadeia Produtiva & 3.250 & 1.083 & 1.200 & $76 \%$ & $24 \%$ & 2,0 & 600 & 902,78 \\
\hline
\end{tabular}

Fonte: Secretaria de Estado de Trabalho, 2000; Araújo, 2002.

O total de recursos movimentados chega a cerca de $\mathrm{R} \$ 416$ milhões e a parcela apropriada pela mão de obra é da grandeza de aproximadamente $\mathrm{R} \$ 181$ milhões. Cabe ressaltar que tais valores não 
incluem as atividades relacionadas à realização do carnaval de rua e dos desfiles dos grupos C, D e E e dos grupos de avaliação e blocos de enredo na Avenida Rio Branco, a realização de diversos eventos promovidos pela Prefeitura e os desdobramentos destes sobre o comércio e seus fornecedores.

\subsection{Iniciativas de ensino e mercado de trabalho}

No que se refere à infraestrutura de ensino e capacitação profissional, verifica-se na região metropolitana uma extensa rede de instituições voltada para a capacitação nas mais diversas atividades acessórias ao carnaval. O mesmo se verifica quanto à atividade turística. Já o ensino especificamente relacionado à atividade criativa conta com uma infraestrutura formalizada apenas em áreas mais gerais, como artes, música, moda e estilismo etc.

Destaca-se a parceria constituída entre a Liesa e a Universidade Estácio de Sá, criando em outubro de 2005 o Instituto do Carnaval, que oferece o curso de graduação profissional, com duração de dois anos, para a formação de "profissionais de carnaval", com foco na Gestão de Festas e Eventos Carnavalescos. ${ }^{14}$ Foi firmada uma parceria entre a coordenação do instituto e as escolas de samba Acadêmicos da Abolição, Arrastão de Cascadura e Boêmios de Inhaúma, garantindo aos estudantes do curso a realização de estágio nas escolas. Além disso, conforme informado por um dos coordenadores do curso, pretende-se, a partir do Instituto do Carnaval, levar para o exterior a formação de pessoas especializadas e qualificadas para transmitirem a cultura brasileira.

No mais, e não menos importante, aponta-se para a infinidade de iniciativas não formalizadas de ensino, envolvendo integrantes de escolas de samba, músicos em geral e, muitas vezes, a própria escola de samba. Grande parte das escolas de samba possui iniciativas de ensino direcionadas a crianças e adolescentes, na forma de oficinas e cursos livres, em áreas como ateliê, adereçagem, música e dança.

As perspectivas de ampliação de cursos de formação de profissionais diretamente ligados ao carnaval se chocam com características do mercado de trabalho nestas áreas, que se revela pouco capaz de absorver um contingente crescente de pessoas, bem como de oferecer ocupações estáveis. Segundo a Secretaria Estadual de Trabalho do Estado do Rio de Janeiro, cerca de 80\% dos postos de trabalho gerados pelas escolas de samba são de caráter temporário e informal. No que se refere especificamente à produção de fantasias e alegorias, esta porcentagem seria de cerca de 62\% (Araújo, 2002).

\footnotetext{
${ }^{14}$ As disciplinas oferecidas cobrem um amplo espectro abrangendo conhecimentos artísticos, sociológicos e antropológicos e de marketing e administração.
} 
A sucessão de etapas distintas (que requerem habilidades distintas) no processo de preparação para o carnaval reforça o caráter temporário das contratações. A remuneração média por trabalhador no barracão variava entre três salários mínimos no grupo de acesso A e quatro salários mínimos no grupo especial (Araújo, 2002). O tempo médio de ocupação varia entre quatro e cinco meses. O maior número de contratações temporárias se dá nos dias em torno do desfile, quando são contratadas cerca de 40 pessoas para zelar pela segurança dos carros na concentração e cerca de 200 empurradores. Apenas poucas pessoas são empregados fixos e exercem funções de administração, secretaria, tesouraria, almoxarifado, cozinha, portaria e segurança, além de um ou poucos profissionais para cada uma das atividades de ferragens, carpintaria, escultura e adereços e costura.

No caso da grande maioria das ocupações geradas pela indústria do carnaval, as pessoas se encontram ocupadas apenas por um período restrito de tempo, sendo obrigadas a terem outras ocupações durante o restante do ano. Especificamente nas áreas nas quais se nota uma ênfase maior por parte de iniciativas de qualificação formal - gestão de escolas de samba e eventos e criação artística -, não existe escassez de profissionais capacitados, embora se verifique a concorrência entre as escolas de samba pelos profissionais mais conceituados. ${ }^{15}$ Isto pode ser verificado avaliando-se os fatores, relacionados à mão de obra, que potencialmente constituem entraves para a operação das escolas de samba. Aproximadamente 67\% dos entrevistados na pesquisa de campo avaliam não existir nenhuma dificuldade relacionada à contratação de pessoas qualificadas - o que vale para pessoas com capacitações técnicas, administrativas ou artísticas. Portanto, existe um espaço limitado para a formação e incorporação no mercado de trabalho formal de um número crescente de pessoas qualificadas em áreas estritamente ligadas ao carnaval.

\subsection{Representação, apoio e promoção}

Em torno das atividades relacionadas ao carnaval, verifica-se uma densa teia de agentes de apoio e promoção e de representação, bem como um alto grau de comprometimento da esfera pública em todos os níveis de governo, mas especialmente no âmbito municipal. Destacam-se as associações representativas das escolas de samba, a Liesa (Liga Independente das Escolas de Samba) que representa as escolas do grupo especial e a AESCRJ (Associação das Escolas de Samba da Cidade do Rio de Janeiro), representante das demais escolas de samba. Como mencionado acima, a Liesa foi

\footnotetext{
${ }^{15}$ Verifica-se uma crescente profissionalização em diversas áreas artísticas ligadas à produção e realização do desfile das escolas de samba e à disputa das agremiações por profissionais de renome. Tal processo ocorre em detrimento da atuação de artistas tradicionalmente ligados a uma agremiação específica. Este processo se verifica em atribuições como: carnavalesco; mestre de bateria; compositor e intérprete; mestre-sala e porta-bandeira; coreógrafo etc.
} 
criada em 1984 pelas principais escolas de samba para defender os interesses deste grupo privilegiado. A AESCRJ é a remanescente da associação que representava todas as escolas de samba. Junto com a Riotur, estas organizações constituem as principais instâncias de coordenação das atividades relacionadas ao carnaval.

As associações são responsáveis pela distribuição entre suas associadas das subvenções concedidas pelo governo municipal e estadual. ${ }^{16}$ Elas firmam os contratos relacionados à organização do evento no sambódromo junto à Riotur e, no caso da Liesa, junto à emissora de televisão para transmissão do desfile. Estas associações também são responsáveis, desde 1992, por estabelecerem as regras básicas para os desfiles e da competição entre as escolas de samba, contratando os jurados para avaliação dos quesitos estabelecidos.

Um ator fundamental, tanto na organização das festividades, como no apoio a escolas de samba, é o poder público. O poder público apoia, desde a década de 1960, as atividades e a realização do desfile das escolas de samba. A primeira forma de envolvimento na provisão de infraestrutura para o desfile data de 1962, com a construção de arquibancadas na Avenida Rio Branco (Ferreira, 2004).

Posteriormente foram instaladas cabines para os jurados e uma passarela para a instalação de câmeras de TV e das estações de rádio. Outro marco foi a construção do sambódromo pelo governo do estado em 1984. A construção da 'Cidade do Samba' representa o mais recente e expressivo investimento da Prefeitura e vem atender a demanda das escolas de samba por melhores condições de infraestrutura para a confecção do espetáculo.

A Prefeitura da cidade, através da Secretaria Municipal de Turismo - Riotur, investe uma quantia considerável para a provisão da infraestrutura necessária à realização do desfile das escolas de samba no sambódromo e do carnaval de rua, mobilizando diversos órgãos relacionados à segurança pública, limpeza urbana, iluminação, saúde etc. ${ }^{17}$

\section{Atratividade e sustentabilidade}

\footnotetext{
${ }^{16}$ A partir de 1989, os recursos referentes à participação das escolas na receita gerada pelo desfile não são mais divididos igualmente entre as escolas do grupo especial, como ocorria até então, mas em ordem decrescente de acordo com a colocação final de cada escola de samba no último carnaval. Assim, a escola que se sagrou campeã recebe um valor cerca de $20 \%$ superior (o que equivale a cerca de R $\$ 500$ mil) à escola no extremo inferior do ranking - no caso a escola que acaba de ascender ao grupo especial.

${ }^{17}$ Em 1999 a Prefeitura destinou R\$ 8.899.769,00 para a consecução do evento. A Riotur firmou 23 contratos de obras e serviços de engenharia e 34 de locação e prestação de serviços (Instituto Pereira Passos e Secretaria Especial de Assuntos Estratégicos, 1999).
} 
No que se segue, são discutidos os aspectos que contribuem para a criação e preservação da sustentabilidade em um sistema baseado em uma atividade cultural. Seguindo a abordagem conceitual e metodológica de ASPILs, baseada no marco teórico evolucionário, analisamos questões como o processo de inovação, os fatores determinantes da competitividade, a criação e difusão do conhecimento, a cooperação e a coordenação das atividades.

\subsection{Inovação}

As primeiras contribuições que lidam especificamente com aspectos relacionados com a inovação em serviços e, igualmente, em atividades culturais caracterizam tais atividades como incorporadores de avanços tecnológicos originados de outros setores da economia. ${ }^{18}$ Estudos recentes sugerem que os serviços inovam, mas com diferentes características e graus de intensidade (Sundbo e Gallouj, 1998). Ênfase especial é dada aos setores considerados importantes devido à sua contribuição e impacto sobre as dinâmicas inovadoras na indústria, seja identificando alguns serviços como coordenadores de atores e esforços inovativos voltados para a geração de novas tecnologias seja como parceiros de empresas manufatureiras. ${ }^{19}$

O grupo de atividades analisado no presente estudo é classificado - sob a perspectiva desses estudos - exatamente como serviços relegados à posição passiva descrita acima, em que aumentos de eficiência ocorrerem quase só através da incorporação de máquinas e equipamentos procedentes de outros setores. Em muitos estudos empíricos que tentam identificar padrões de inovação para diferentes tipos de serviços, as atividades relacionadas ao entretenimento e cultura são classificadas como dominadas por fornecedores e menos inovativas, realizando apenas pequenas inovações incrementais (Miles, 2001). ${ }^{20}$

Geralmente, o foco da análise é direcionado à contribuição dos serviços para a inovação em bens tangíveis, não levando em conta que a inovação em intangíveis pode representar um elemento significativo de competitividade (Howells, 2000). Assim, ressalta-se que as atividades culturais (ou

\footnotetext{
${ }^{18}$ De acordo com a classificação de Pavitt (1984), por exemplo, todas as atividades do setor de serviços são “dominadas por fornecedores". Miles (2001) sugere que, talvez influenciado pelas inovações em serviços, este autor tenha adicionado a sua taxonomia, no texto de 1994, a categoria de "intensivos em informação".

${ }^{19}$ Ênfase especial é atribuída aos chamados "serviços empresariais intensivos em conhecimento" (Knowledge intensive business services - KIBS), já que essas atividades não se enquadram no estereótipo de setores dominados por fornecedores e apresentam forte interação com o setor manufatureiro (Howells, 2000).

${ }^{20}$ A tendência recente de transformação e reorganização da estrutura industrial em atividades como a música, o audiovisual, as artes cênicas etc. tem sido analisada, predominantemente, sob a perspectiva do impacto da introdução de novas tecnologias que possibilitaram uma redução substancial dos custos de produção e reprodução (Throsby, 1994; Bustamante, 2004; Hoskins et al, 1994 e Kretschmer, 2001).
} 
criativas) são caracterizadas como entre as mais inovadoras da economia mundial (Flew, 2002). Na mesma direção, pode-se argumentar que os outros setores de serviços analisados neste estudo possuem o potencial para gerar inovações em produtos importantes, com impacto significativo para sua competitividade.

A análise da inovação de produto nessas atividades, bem como os fatores que a influenciam e o impacto sobre a competitividade, sugere uma ampliação da definição de inovação. Um primeiro ponto a ser considerado refere-se ao que, de fato, é um novo produto.

Como sugerido por Sundbo (1997) em relação a esses tipos de serviços classificados como serviços pessoais (que assumem uma forma única em cada transação), é difícil identificar o que, de fato, é uma inovação. $\mathrm{O}$ autor sugere uma escala que vai desses casos considerados corretamente como inovações até aqueles casos caracterizados como atos individuais de aprendizagem. Entre os extremos, encontramos uma escala contínua variando entre maiores e menores inovações "incrementais". Uma característica semelhante pode ser verificada no caso de atividades culturais. Como caracterizado por Cunningham (2002), cada novo produto é único, diferenciado e sem substitutos próximos. E essa diferenciação de produtos não deriva necessariamente de uma decisão estratégica em um sentido econômico. No entanto, muitos autores (Bilton e Leary, 2002; Castañer e Campos, 2002) sugerem diferentes níveis de "intensidade" da inovação. Em primeiro lugar, podemos caracterizar alguns casos como inovações "correntes" que levam à variedade de produtos similares. Mas também se podem identificar inovações de impacto significativo - e também com maior potencial econômico - que mudam os padrões estabelecidos. Onde um produto cultural específico está localizado nesta escala é difícil de definir no momento da sua criação, sendo essa classificação só possível ex-post (e, mesmo assim, com algum grau de subjetividade associada a esta avaliação).

Para uma melhor caracterização dos aspectos que influenciam as atividades inovadoras, podemse caracterizar os elementos que influenciam os esforços e estratégias criativas, conforme proposto na literatura que discute a variação inter-sectorial dos padrões de inovação (Malerba e Orsenigo, 1997 e Dosi, 1988). Os seguintes pontos em relação a atividades culturais podem ser ressaltados: ${ }^{21}$

- Mesmo que os elementos de oportunidade tecnológica sejam importantes, o potencial de inovação não é, de longe, limitado por este aspecto. Os principais insumos para a criação de novos produtos culturais residem no "conhecimento cultural e artístico" dos agentes criativos e na sua criatividade. Ele é um recurso não escasso, oferecendo uma variedade quase infinita de possibilidades para a criação de novos produtos.

\footnotetext{
${ }^{21}$ Para uma discussão detalhada ver Matos (2006).
} 
- Embora as condições de apropriabilidade pareçam ser muito frouxas em serviços em geral, no caso de atividades culturais encontramos um sistema consolidado de direitos de propriedade intelectual oferecendo um incentivo importante para os esforços criativos. ${ }^{22}$ Porém, as condições de apropriabilidade não são essenciais. Atividades culturais ultrapassam uma lógica puramente econômica e o criador não procura necessariamente a comercialização de sua obra. O elemento chamado "prazer pessoa" é um importante determinante para a criação artística (Throsby, 1994; Bilton e Leary, 2002). ${ }^{23}$

- Os produtos culturais, bem como os serviços pessoais, são "bens de experiência". Há um nível particularmente elevado de incerteza, uma vez que não é possível prever o seu sucesso comercial. Cada "novo" produto envolve um alto grau de risco, uma vez que grande parte das despesas e esforços para a sua criação não pode ser recuperada - são custos irrecuperáveis. Tal aspecto pode representar um fator que inibe a criação e inovação. Mas produtos artísticos são caracterizados por sua rápida obsolescência e, dada a ampla variedade existente, o mercado potencial para cada obra é relativamente restrito. A criação de novos produtos torna-se um imperativo para empreendimentos artísticos, apesar do alto risco envolvido. E, uma vez que apenas uma pequena fração alcança o sucesso comercial, é um imperativo extrair o máximo de retorno desses produtos (O'Connor, 1999).

- Pode-se argumentar que não há significativa cumulatividade em relação à atividade criativa (inovadora) em serviços e atividades culturais. Especialmente as atividades culturais são marcadas pela constante criação de produtos altamente diferenciados que podem ou não representar uma continuidade em relação aos esforços anteriores. Mas a base de conhecimento associada representa um elemento importante que influencia e limita as possibilidades criativas.

- Os contextos sociais e culturais específicos englobam uma base de conhecimento cultural específica que influencia a criação artística, em termos de códigos, símbolos e temas que são empregados. A base de conhecimento cultural é em grande parte de natureza tácita, estando diretamente associada a um contexto social e territorial específico, em que o conhecimento é gerado e difundido através da interação direta entre os agentes.

\footnotetext{
${ }^{22}$ No entanto, como argumentado por muitos autores (Robbins, 1963; Baumol e Bowen, 1966; Peacock, 1969; Scitovsky, 1972; Owen e Wildman, 1992), produtos culturais possuem um caráter de bem público que está em contradição com as tentativas de se apropriar de forma privada dos retornos associados à criação de uma obra de arte (Caves, 2000; Hoskins et al., 1994). Assim, as condições de apropriabilidade variam entre as diversas atividades culturais, bem como de acordo com a importância atribuída em cada sociedade às suas características de bens públicos ou de bens meritórios e a forma como isso impacta sobre os contextos institucionais.

${ }^{23}$ Este aspecto é o que Caves (2000) caracteriza como ars gratia artis, a arte para artes. Essa característica, somada ao fato de que a criatividade - o principal insumo para a inovação - não é um fator escasso ou caro, implica uma força motriz adicional para a atividade inovativa.
} 
- Como sugerido por Throsby (1994), mesmo que a criatividade seja um elemento essencialmente individual, a matéria-prima empregada (o conhecimento relevante) e a atividade artística em geral são fortemente marcadas por seu caráter coletivo e sistêmico.

O caso do carnaval reflete muitos destes aspectos. Em primeiro lugar, é importante destacar a grande capacidade de inovação associada à constante criação de novas performances com suas fantasias, alegorias e músicas. Algumas respostas ao questionário durante a pesquisa de campo ilustram a importância da inovação.

Verifica-se que a novidade constante representa um fator fundamental para preservar a capacidade de atração do desfile. Não é provável que o mesmo espectador goste de ver exatamente o mesmo desfile por mais de uma ou duas vezes. Embora todas as escolas de samba tenham que observar regras sobre a forma de estruturar o desfile, a cada apresentação de cada escola de samba se verificam elementos completamente novos que estão sendo expostos pela primeira vez. Isso representa um elemento fundamental para renovar a atratividade.

No caso do carnaval, também não é possível atender a diferentes "consumidores" ao longo do tempo e extrair o máximo de retorno de um espetáculo, porque a transmissão do desfile pela televisão expõe os elementos de novidade para todos. A importância da constante renovação pode ser verificada quando se consideram alguns dados sobre os espectadores no desfile em 2005. A pesquisa mostrou que $61 \%$ eram do Estado do Rio de Janeiro, 21\% eram brasileiros de outros estados e de 18\% turistas estrangeiros. Dentre os fluminenses, $69 \%$ dos espectadores já tinham assistido ao carnaval nos últimos anos e o número médio de vezes que eles tinham ido ao desfile era de 6,4. No caso de brasileiros de outros estados, estes dados eram de $43 \%$ e 5,5 vezes e, para estrangeiros, $18 \%$ e 3,4 vezes. Isto ilustra a importância da inovação constante do espetáculo, uma vez que não seria provável que a mesma apresentação estimulasse tantas pessoas a voltarem repetidas vezes.

A inovação também é estimulada por meio da competição estabelecida entre as escolas de samba. Uma vez que o espectador paga para assistir a todas as apresentações de um grupo (em um dos dias de desfile), as escolas de samba não podem competir entre si pelo público. Neste sentido, a competição formal estabelecida entre as escolas de samba substitui este mecanismo de mercado (que está ausente no nível de cada organização), estimulação de constantes esforços para inovar e se destacar das demais.

Em linha com a discussão apresentada acima, pode-se pensar na inovação em atividades culturais sob duas perspectivas. A distinção de inovações "corriqueiras" com pouco impacto sobre as estratégias dos concorrentes e inovações "substanciais". Essas inovações "paradigmáticas" podem ser 
identificadas na evolução histórica da festa. Há muitos exemplos de inovações que deram a uma escola de samba um campeonato ou uma hegemonia por alguns anos e que, posteriormente, foram absorvidos por todas as escolas de samba, transformando-se em um elemento obrigatório para as apresentações. Poderíamos citar a introdução das alegorias nos desfiles, a criação da comissão de frente com performances teatrais em substituição aos integrantes tradicionais das escolas de samba ou a modificação do samba de enredo, introduzindo melodias e letras de simples memorização, etc. Estas principais inovações transformaram uma manifestação de rua inicialmente popular em um espetáculo mundialmente conhecido, atraindo o interesse de um número crescente de pessoas. Elas são, de alguma forma, diferentes das inovações "regulares" descritas acima, uma vez que tiveram um impacto duradouro sobre a estratégia criativa de seu criador e os concorrentes e, assim, em todo o desfile.

Em linha com a discussão acima, as condições de apropriabilidade não são relevantes para o caso das atividades criativas do carnaval. Diferente de outras atividades culturais, cada novo produto (toda a apresentação) é "vendido" apenas uma vez e depois perde o seu valor. Então, não há oportunidade para o concorrente para ser um imitador em relação às "inovações comuns". A proteção dos novos elementos é importante apenas antes da apresentação. Cada escola de samba esconde suas principais inovações dos concorrentes e do público até o carnaval. Em relação às "grandes" inovações, a imitação acontece sem qualquer problema. De qualquer forma, estes seriam expostos ao público pelo imitador apenas um ano mais tarde. $\mathrm{O}$ imitador que não introduz novos elementos por si somente atinge uma posição regular na competição. Isto representa uma força que empurra todas as escolas de samba a serem constantemente inovadoras.

A escola de samba como um todo, o carnavalesco que cria os novos conceitos estéticos ou os artesãos que materializam esta criação não recebem pagamentos associados aos seus direitos de propriedade intelectual. $\mathrm{O}$ único caso em que o direito autoral tem alguma relevância é na música, com as execuções públicas dos sambas. Mas essa fonte de renda representa uma quantidade insignificante em comparação com os custos envolvidos na produção do espetáculo. Isto leva à conclusão de que a falta de condições de apropriabilidade, de nenhuma forma, limita ou dificulta a inovação nesta atividade cultural.

O risco potencial associado à produção de um novo espetáculo que envolve milhões de dólares é reduzido devido à fama do carnaval. É certo que haverá demanda suficiente por um espaço no sambódromo, que haverá número suficiente de pessoas dispostas a pagar pelas fantasias para participar do desfile e que o canal de TV terá audiência suficiente, de forma a estar disposto a pagar pelos direitos de transmissão. Esta certeza existe por causa da fama desse espetáculo, não a fama de uma única escola 
de samba ou artista. Isso nos leva a considerar a importância do nível coletivo, que será discutido na seção sobre a competitividade.

Além da compreensão das características particulares de inovação em atividades culturais, propõe-se a reconsideração desses esforços que podem levar a um diferencial competitivo. A competitividade de um empreendimento artístico, um conjunto de atividades artísticas ou culturais ou de um sistema baseado em tais atividades pode ser associada ao que está em direta oposição à noção de inovação. As características intrínsecas da cultura levam ao que Laraia (2002) caracteriza como o choque entre tendências conservadoras e inovadoras - duas forças aparentemente contraditórias que se complementam no processo dinâmico de evolução da cultura. Ambos, preservação e inovação, refletem dois lados de um mesmo processo de geração de algo novo, em que o passado é reproduzido, atualizado, modificado ou até mesmo negado (Gil, 2004). Portanto, no caso específico de atividades artísticas e deste estudo, faz-se necessária a extensão desse conceito, entendendo-o como a geração do "novo", mesmo que reproduzindo e preservando o que é velho (Matos e Lemos, 2005).

Para as escolas de samba, a preservação de aspectos característicos desta manifestação cultural é tão importante quanto a inovação para a atratividade do espetáculo. Ambos os esforços se complementam. A criação de novos elementos é enquadrada pela necessidade de inserir as inovações no contexto de toda a apresentação em uma forma harmoniosa. Em relação aos elementos a serem preservados, os itens mais citados pelos entrevistados durante a pesquisa de campo foram o ritmo do samba e seus instrumentos tradicionais e alas específicas da comunidade, como as alas da velha guarda e das crianças. A ênfase nesses dois setores - os antigos e os novos sambistas - aponta também para a importância da preservação dessa manifestação cultural em uma perspectiva de prazo de convergência de diferentes gerações.

Durante a pesquisa de campo, os entrevistados foram questionados sobre alguns impactos potenciais das atividades inovadoras. $\mathrm{O}$ item ao qual foi atribuído o maior índice de importância ${ }^{24}$ foi a atração de mais espectadores ou consumidores para o desfile e para as festividades na sede (índice de importância de 0,96). Em segundo lugar vem a atração de novos tipos de espectadores e consumidores $(0,91)$. Em terceiro lugar vem a qualidade das atrações que promovem $(0,84)$ e, em quarto, a obtenção de um maior reconhecimento e fama $(0,74)$. Estas respostas sublinham a importância do espectador ou consumidor para atividades culturais. Uma vez que se trata de "bens de experiência", agradar o

\footnotetext{
${ }^{24}$ Aos entrevistados foi solicitado que atribuíssem um grau de importância a diferentes aspectos. As respostas possíveis eram: não tem importância, baixa, média ou alta importância. O índice de importância é construído da seguinte forma: Índice $=\left(0 * \mathrm{~N}^{\mathrm{o}}\right.$ nenhuma importância $+0,3 * \mathrm{~N}^{\mathrm{o}}$ de baixo $+0,6 * \mathrm{~N}^{\mathrm{o}}$ médio $+\mathrm{N}^{\mathrm{o}}$ alto $) /\left(\mathrm{N}^{\mathrm{o}}\right.$ de respondentes $)$. Portanto, este índice varia entre 0 e 1 .
} 
consumidor é a principal motivação para os esforços inovadores, em detrimento de outros objetivos, tais como a redução de custos, o aumento da eficiência ou preocupações ambientais.

\subsection{Os processos de aprendizagem}

Tal como proposto acima, as atividades criativas das escolas de samba são influenciadas pela "base de conhecimento cultural" específica. Esta é de natureza essencialmente tácita e enraizada na Região Metropolitana do Rio de Janeiro e, especialmente, nas comunidades de onde surgiram as escolas. Como descrito acima, o samba e o desfile evoluíram ao longo de décadas neste território, o que está intimamente associado com a evolução e transformação de toda a cidade. As capacitações associadas à atividade essencialmente artística e criativa, bem como aquelas de caráter técnico e organizacional, fazem esta manifestação cultural única e impossível de ser copiada em outro contexto. Como sugerido por Lastres e Cassiolato (2005), o conhecimento tácito, no caso de qualquer atividade produtiva, é um recurso específico de cada localidade, possivelmente constituindo um importante elemento de diferenciação e vantagem competitiva. Assim, ainda mais evidente do que em atividades industriais, este conhecimento representa um diferencial do sistema em foco.

Os diferentes tipos de conhecimento, bem como os mecanismos de difusão, possuem características específicas no caso de aglomerações baseadas em atividades culturais. Talvez o conhecimento mais importante é aquele que influencia o que pode ser chamado de "qualidade" ou "atratividade" de atividades culturais.

Conforme proposto por Filer (1986), a experiência acumulada e as habilidades desenvolvidas ao longo do tempo são determinantes para o sucesso de um artista. Além disso, em muitos casos, o nível de educação formal pode ser menos significativo para explicar as variações na renda em atividades artísticas. As habilidades relevantes para o sucesso profissional não são facilmente transmitidas na educação formal. Além disso, Throsby (1994) sugere que a dificuldade de identificar fatores objetivos que influenciam os níveis de remuneração aponta para o papel fundamental do "talento". Tais observações enfatizam a importância do conhecimento tácito na forma de habilidades dos agentes criativos em atividades culturais. O'Connor (1999) caracteriza este tipo de conhecimento como “conhecimento cultural ou simbólico", uma vez que está associado a simbolismos (valores, hábitos etc.) que são específicos de cada grupo social. Além do processo de aprendizagem durante as atividades do dia a dia (learning-by-doing), os processos interativos de aprendizagem desempenham um papel central para a difusão deste conhecimento tácito "cultural". 
Tal conhecimento constitui, portanto, um recurso único de um grupo social, possivelmente constituindo um importante diferencial competitivo. Throsby (1999 e 2001) caracteriza este ativo como "capital cultural". É um estoque de "riqueza" no domínio de uma sociedade. O valor cultural, consequentemente, existe naqueles bens e serviços que contribuem para a manutenção e ampliação deste estoque. A questão é em que medida este "trunfo" pode representar, efetivamente, um elemento de competitividade dinâmica ou sustentável. A escolha do termo capital sugere, a longo prazo, que este estoque possa se depreciar.

Assim, considerando o seu potencial para o desenvolvimento, é importante entender como o ambiente específico em que uma atividade cultural está inserida favorece ou até mesmo impõe obstáculos a esta atividade. Neste contexto, a "manutenção" e a ampliação desse estoque de riqueza estão diretamente associadas com a sua difusão entre os agentes locais, a sua transformação através do processo criativo, bem como a preservação das características-chave que o tornam único. No entanto, a possibilidade de "corrosão" desta base de conhecimento não pode ser descartada.

Nas atividades associadas ao carnaval encontramos uma base de conhecimento de caráter essencialmente tácito. Como proposto por Malerba e Orsenigo (1997), quão mais tácito, complexo, sistêmico é esse conhecimento, maior será a importância dos mecanismos de aprendizagem interativa entre os agentes próximos. Essa tendência pode ser verificada com ainda mais ênfase no caso do carnaval.

A ênfase na aprendizagem através da experiência do dia a dia pode ser verificada, considerando as respostas dos diretores das escolas de samba com relação às atividades de formação, tanto no campo artístico quanto no técnico. Todas as escolas de samba que estavam envolvidas em algum tipo de esforço de formação atribuíram alta importância para os cursos oferecidos dentro da organização. E 75\% atribuíram alta ou média importância para a absorção de mão de obra especializada que já esteve envolvida em atividades relacionadas ao carnaval. Na mesma linha, quando questionados sobre a importância das diferentes fontes de informação, todas as escolas de samba atribuíram grande importância às fontes internas. Em oposição, os cursos formais e a absorção de trabalhadores de outras localidades foram considerados sem importância pela maioria.

Além disso, um aspecto considerado de importância central é o esforço para preservar e fazer valer as vantagens comparativas assentadas sobre a base cultural específica. Este esforço está diretamente ligado à transmissão deste conhecimento através das gerações. Todas as escolas de samba dão ênfase à integração de crianças de suas comunidades em atividades artísticas. Muitas escolas de samba também possuem uma escola de samba mirim, que é formada apenas por crianças e 
adolescentes. Os processos de aprendizagem que resultam dessas atividades constituem, talvez, o processo mais importante para a sustentabilidade do sistema de carnaval no longo prazo.

Também as relações interativas das escolas de samba com fontes de informação fora das organizações se revelaram muito importantes. Como esperado, no caso da maioria das atividades culturais, onde fama e reconhecimento são de importância central, as fontes de informação consideradas de maior importância são a mídia e os clientes ou espectadores. Saber o que agrada ao público é de importância central para os artistas da escola de samba para direcionar suas atividades. E essa informação vem diretamente através dos espectadores ou através dos meios de comunicação.

Outros agentes de grande importância para $73 \%$ das escolas de samba são os fornecedores de matérias-primas e equipamentos. Este dado, por um lado, confirma as fortes ligações entre as atividades culturais e seus fornecedores. Essa interação é diretamente relacionada com a atividade criadora. Como ressalta Cavalcanti (1995), os carnavalescos estão constantemente à procura de novos itens para adorno que permitem a criação de novos efeitos visuais em fantasias e carros alegóricos. Novos equipamentos são fundamentais para a criação de novos efeitos especiais, como, por exemplo, as esculturas de luz em movimento e efeitos de água, etc.

Outras fontes importantes de informação são o governo local - uma vez que este possui uma central para a coordenação das muitas atividades que convergem para a realização das festividades durante o carnaval - e a internet - uma vez que constitui uma importante fonte de informação,

sobretudo para o desenvolvimento dos enredos (fatos históricos, personalidades, lugares, etc, que constituem a linha guia para os desfiles). Em oposição, as universidades (mesmo no campo artístico) não constituem importantes fontes de informação para a maioria.

Finalmente, é importante ressaltar que quase todos os atores que constituem fontes de informação (com maior ou menor importância) estão localizados na região metropolitana da cidade do Rio de Janeiro. Esta descoberta enfatiza o caráter localmente integrado da base de conhecimento relevante. Considerando-se que os encontros de lazer foram considerados entre os lugares mais importantes para a troca de informações, isto enfatiza o caráter altamente espontâneo e informal das interações.

\subsection{Cooperação e coordenação}

Aponta-se para a consolidação de práticas de cooperação como forma de intensificar e ampliar os potenciais impactos da interação entre os agentes em ASPILs. Britto (2004) sugere que a cooperação 
possa levar a três impactos básicos. Em primeiro lugar, a consolidação de práticas de cooperação é um mecanismo eficaz de processamento de informações, possibilitando aglutinar competências complementares e aumentar a eficiência produtiva e o potencial inovativo dos agentes envolvidos. Em segundo lugar, a cooperação permite enfrentar turbulências do ambiente econômico e identificar novas oportunidades. Por fim, práticas cooperativas podem levar, a longo prazo, à facilitação da comunicação entre os agentes, possibilitando uma melhor integração de competências, a consolidação de princípios de "confiança mútua" e uma maior sincronização das ações estratégicas dos agentes envolvidos.

A cooperação entre agentes em ASPILs potencialmente possibilita a divisão dos esforços e custos do processo inovativo e o compartilhamento do risco associado a estas atividades, além de representar um meio eficaz para o aprofundamento do aprendizado por interação. Em muitos casos, especialmente no caso de empresas de menor porte, os custos e riscos associados implicam a impossibilidade de empresas individuais se dedicarem a tais atividades, representando a ação conjunta uma alternativa viável para o desenvolvimento de novos produtos e processos produtivos (Lemos, 2002).

A cooperação se mostra especialmente significativa em atividades de base cultural, dado que a estreita interação produtiva/criativa está intimamente ligada ao caráter coletivo da produção e consumo artístico e cultural e à grande complementaridade entre os diversos atores e suas capacitações, incluindo atividades criativas e outros agentes necessários para se chegar ao produto final. Cada participante precisa apresentar algum nível de eficiência para o sucesso ou qualidade de um bem ou serviço cultural (Caves, 2003). Especificamente, no caso de um sistema produtivo e inovativo centrado em atividades de base cultural inseridas no contexto de uma festividade, o fator determinante da competitividade não se origina na estratégia de um único empreendimento, mas sim da soma das estratégias e qualidade dos produtos e serviços oferecidos pelo conjunto dos empreendimentos envolvidos.

Além disso, considerando ser o bem cultural, sob a ótica econômica de um produto ou serviço a ser comercializado, um bem não essencial, seu consumo depende fortemente do gosto e aceitação do público. Como apontado acima, a interação entre os agentes possibilita a redução e compartilhamento de custos e riscos, que tendem a ser especialmente elevados naquelas circunstâncias.

Os resultados da pesquisa de campo sugerem que, em uma primeira análise, as relações cooperativas não são consideradas muito importantes para as escolas de samba. Somente 30,8\% dos entrevistados afirmaram se envolver em relações de cooperação com outros atores. A forma de cooperação citada com maior frequência pelos entrevistados (que, de fato, não constitui uma relação 
cooperativa, por representar um fluxo unidirecional) foi a doação de materiais das escolas de um grupo para escolas de grupos inferiores. ${ }^{25}$ Estas doações se referem principalmente a fantasias e adereços usadas durante o último carnaval, que não serão reaproveitadas, mas que se revelam úteis para as escolas de samba de grupos inferiores, dado seu menor poder aquisitivo. Uma forma de relação efetivamente cooperativa, que poderia ser esperada - a aquisição comum de insumos para a obtenção de preços melhores - foi citada por apenas uma das escolas de samba entrevistadas.

Esses resultados, em parte, não confirmam a hipótese de que a cooperação é especialmente importante em atividades culturais. Embora cada ator que faz parte da produção do produto, denominado desfile das escolas de samba, tenha que apresentar algum nível de convergência e complementaridade com os demais, isto não parece induzir relações estreitas de interação no nível das organizações.

Todavia, esta análise é baseada nas respostas a uma pergunta específica apresentada no questionário empregado na pesquisa de campo. As entrevistas com os diretores das escolas de samba, bem como com os demais agentes, mostraram que existem relações informais de cooperação, mas que frequentemente não são compreendidas como tais. Os entrevistados reconheceram, mesmo que de forma indireta, a relevância de ações coletivas relacionadas à promoção do carnaval e do desenvolvimento local. O próprio fato de a maioria dos agentes se revelar ciente da importância da identidade cultural e buscar preservar muitas de suas características específicas reflete tal reconhecimento e a convergência de ações para objetivos comuns. De forma geral, verifica-se um maior grau de rivalidade no nível das diferentes escolas de samba, diretamente relacionada à competição durante o desfile. De forma semelhante ao discutido no caso da interação com outros agentes enquanto fonte de informações, observa-se uma constante e intensa interação no nível dos integrantes individuais das agremiações.

A interação entre os diferentes agentes em ASPILs é balizada por diferentes formas de governança. Esta refere-se aos modos de coordenação entre os diferentes atores - o Estado em seus diferentes níveis, empresas locais, organizações de representação e promoção, cidadãos e trabalhadores etc. - e suas atividades, que envolvem da produção à distribuição de bens e serviços, bem como o processo de geração, uso e disseminação de conhecimentos e de inovações (Cassiolato e Szapiro, 2003; RedeSist, 2005). As formas de governança variam de acordo com as características específicas de cada ASPIL, quais sejam, a estrutura de produção, a aglomeração territorial, a organização da(s) indústria(s),

\footnotetext{
${ }^{25}$ A questão referente às formas de cooperação nas quais as escolas de samba estariam envolvidas foi apresentada, no questionário aplicado, tanto como uma pergunta fechada, com a sugestão de formas de cooperação, como também como uma pergunta aberta de livre resposta.
} 
a inserção nos diferentes mercados (do local até o internacional), a densidade institucional e o tecido social (Suzigan et al, 2003).

Especialmente no caso de atividades de base cultural, com inúmeros agentes e complexas interligações que convergem para um produto ou serviço, mostra-se necessária uma efetiva coordenação das diversas atividades. Tal complementaridade se revela especialmente naquelas atividades descritas por Caves (2003) como complexas e com variados inputs, nas quais se verificam inúmeras relações de subcontratação e cooperação. Particularmente no caso de atividades baseadas em manifestações culturais, revela-se fundamental identificar as formas de coordenação deste complexo conjunto de atividades.

Um sistema como o de carnaval, com fortes interdependências, sugere a necessidade de uma forte hierarquia de coordenação orientando os diversos interesses individuais para a constituição de um produto coletivo de qualidade. Como descrito acima, existe uma estrutura central de coordenação das atividades envolvendo o carnaval. Três agentes principais desempenham papéis centrais: a Prefeitura, a Liga Independente das Escolas de Samba do Rio de Janeiro - LIESA, e a associação que representa as demais escolas de samba, a Associação das Escolas de Samba do Rio de Janeiro - AESRJ.

Algumas perguntas feitas durante a pesquisa de campo ajudam a traçar um quadro amplo da avaliação dessas organizações por parte dos agentes culturais. Em relação ao governo local, especialmente a RIOTUR, vale a pena salientar a avaliação positiva unânime desta como um agente de apoio e de coordenação. A avaliação das duas associações também é muito positiva. O papel central destas associações para a coordenação das atividades fica evidente, considerando o índice de importância atribuída à sua contribuição para a definição de objetivos comuns para o carnaval $(0,78)$. A importância da sua articulação com o governo local é sublinhada pela importância atribuída a seus esforços voltados para a apresentação das reivindicações coletivas $(0,84)$. Outras contribuições com uma avaliação média são: incentivo para as relações de cooperação, criação de fóruns de discussão e provisão de infraestrutura auxiliar às apresentações.

\section{Atratividade e sustentabilidade}

A abordagem de ASPILs tem como foco de análise os aspectos discutidos acima, buscando analisar a atividade produtiva e inovativa sob uma ótica sistêmica, ou seja, contemplando a multiplicidade de agentes econômicos e não econômicos e demais fatores que balizam e dão traços específicos a tal processo. A ênfase nestes aspectos converge para identificar os elementos que podem 
levar a uma maior atratividade do sistema e dos agentes individuais. Especificamente, trata-se de reconhecer os fatores que podem convergir para a constituição de vantagens competitivas dinâmicas, ou seja, que se renovem ao longo do tempo pelo processo contínuo de aprendizagem e aprimoramento das competências. ${ }^{26}$

Em relação a esta discussão se desdobram algumas colocações especificamente relacionadas a atividades de base cultural, bem como ao conjunto de serviços em um sistema como o estudado. Embora se argumente que muitos serviços apresentem condições crescentes de serem transacionados para além de espaços geográficos específicos (Howells, 2000), o grupo de serviços que lida diretamente com o consumidor é, até certo ponto, protegido da concorrência externa. Em tese, esta proteção pode atuar como um fator que limita os esforços destes empreendimentos com vistas a uma maior eficiência produtiva e qualidade dos produtos.

Porém, no caso de atividades de entretenimento e de turismo, a qualidade dos serviços oferecidos é de suma importância, tanto ao nível micro quanto ao nível mesoeconômico. ${ }^{27}$ As múltiplas opções de entretenimento competem entre si pelo limitado tempo livre do consumidor dedicado ao lazer, apresentando, portanto, algum grau de substitubilidade entre si (Earp, 2002). Principalmente em grandes centros urbanos com uma grande variedade de opções de lazer, a atratividade e a qualidade dos serviços se tornam de suma importância. Além disso, o conjunto dos atrativos e serviços turísticos em uma dada localidade compete pelo consumidor no âmbito mundial, buscando constituir um grau de atratividade superior ao de outros possíveis destinos turísticos similares. Tal competição pode se dar entre categorias similares de turismo, como turismo esportivo, ecológico, histórico, cultural etc.

Esta discussão ressalta a importância do caráter coletivo de esforços produtivos e inovativos em tal sistema. Conforme discutido por Throsby (2003), a produção e o consumo da cultura são fenômenos fundamentalmente coletivos. A ênfase e foco de análise no indivíduo (especialmente considerando a inovação, baseada na apropriação privada dos resultados, como a motivação central) não permite, por si só, entender a dinâmica deste sistema. Mostra-se necessário avançar para além das estratégias individuais e analisar as estratégias, inovações e esforços de preservação que são empreendidos coletivamente e cujos resultados são apropriados, igualmente, de forma coletiva. Esta constitui a

\footnotetext{
${ }^{26}$ A concepção de vantagem competitiva sustentável e dinâmica se coloca em oposição à noção de "competitividade espúria" (Fanjzylber, 1988) ou "estática", baseada em preços reduzidos possibilitados pelo pagamento de salários baixos, o uso intensivo de recursos naturais sem uma perspectiva de longo prazo, assim como o uso de taxas cambiais e de juros com finalidades comerciais de curto prazo (RedeSist, 2005). Neste trabalho opta-se pelo uso do termo atratividade, em detrimento de competitividade, ao serem referenciadas atividades de base cultural, dado que estas não se inserem, necessariamente, em uma dinâmica estritamente econômica.

${ }^{27} \mathrm{O}$ nível mesoeconômico se refere a estruturas intermediárias entre os indivíduos e a economia como um todo, enfocando conjuntos de agentes, com uma delimitação espacial ou setorial.
} 
instância central, na qual são estabelecidas as vantagens comparativas com relação a outras opções de lazer ou destinos turísticos.

Uma vez que nenhum agente individual pode se apropriar desses resultados de forma exclusiva, a importância da esfera coletiva é enfatizada. Foi o governo do Estado do Rio de Janeiro que construiu o sambódromo e foi o governo local que construiu a "Cidade do Samba". Estas grandes "inovações" na infraestrutura para a preparação e para o próprio desfile constituem alguns exemplos notáveis de "inovações coletivas" que levaram a transformações positivas importantes de todo o sistema.

Considerando-se as respostas das escolas de samba durante a pesquisa de campo sobre os fatores considerados importantes para a sua competitividade, podemos destacar alguns resultados. Alguns dos elementos com índices altos de importância foram: a infraestrutura física do desfile $(0,93)$, a publicidade e a fama associadas com o carnaval como um todo $(0,87)$ e a cultura local $(0,80)$. Estas respostas sublinham a importância de uma perspectiva de competitividade em nível coletivo. A infraestrutura para o espetáculo depende da qualidade de produtos e serviços de muitos agentes diferentes. A cultura local, a fama e a publicidade também são aspectos que residem e são construídos em um nível coletivo.

Com base nas considerações acima, sugere-se que um importante elemento de atratividade em um sistema como o do carnaval reside na soma e complementaridade das muitas atividades e atores envolvidos. Isso enfatiza a promoção da competitividade no nível coletivo, o que depende da qualidade dos serviços de cada ator, bem como sobre a convergência de suas estratégias. Essa perspectiva reforça a importância do estabelecimento de relações de cooperação entre os atores, bem como a necessidade de uma coordenação eficaz das atividades.

\section{Conclusões}

O presente estudo apresentou um sistema com atividades produtivas que são naturalmente enraizados em um território específico, sugerindo que este possua um diferencial competitivo natural devido ao caráter único do ambiente cultural local. Mas, como argumentado no texto, este diferencial não é espontaneamente sustentável e os esforços voltados para a preservação, manutenção e renovação das atrações são necessários. Assim, é importante identificar quais os fatores que contribuem para a manutenção da capacidade de atração e de sustentabilidade do presente sistema. Este estudo aponta para alguns aspectos importantes a serem considerados: a relação entre inovação e preservação, a importância do nível coletivo e a difusão da base de conhecimento específico. 
Como discutido no texto, os esforços voltados para a constituição dessa atratividade podem incluir tanto a inovação quanto a preservação, no entanto, não se presume que estes sejam esforços mutuamente excludentes. Isto, porém, não sugere que não possam existir pontos de tensão entre a preservação dos aspectos cruciais desta manifestação cultural e sua adaptação para a exploração econômica.

Tanto a superação da potencial tensão entre preservação e inovação quanto o desenvolvimento sustentado apontam para a importância do nível coletivo. Conforme sublinhado no texto, a produção e o consumo desta manifestação cultural é um fenômeno fundamentalmente coletivo. A solução de conflitos potenciais em um sistema complexo que envolve uma variedade de agentes produtivos salienta a importância da coordenação centralizada exercida pelas associações representativas e o poder público. Além disso, o estudo mostra a importância de considerar essas inovações que ocorrem em um nível coletivo, beneficiando todos os agentes do sistema. A evolução histórica do samba e do desfile com destaque para as principais inovações e transformações de toda a estrutura - são essenciais para identificar por que essa manifestação cultural se tornou uma atração mundialmente conhecida.

A abordagem metodológica e analítica desenvolvida pela RedeSist representa uma ferramenta útil para compreender a contribuição de atividades culturais para o desenvolvimento social e econômico. Argumenta-se que uma abordagem sistêmica permite contemplar o fenômeno do carnaval além do foco restrito sobre os agentes individuais, considerando as atividades correlatas e agentes locais. Outros instâncias e atores, como aqueles relacionados ao turismo, educação e organizações culturais, organizações de apoio e promoção e o próprio território dão a este sistema contornos específicos. Ao contemplar as potencialidades e desafios para o desenvolvimento, é necessário considerar as limitações e potencialidades determinadas por essas outras instâncias. O foco na cooperação, aprendizagem e governança nos permite analisar os fatores que são essenciais para a promoção das atividades culturais, visando garantir a sustentabilidade deste sistema. 


\section{Referências Bibliográficas}

ARAÚJO, P. Q. Escolas de samba e relações de trabalho: entre a passarela e o barracão. In: EARP, F. S. (org.) Pão e circo: fronteiras e perspectives da economia do entretenimento. Rio de Janeiro: Palavra e Imagem, 2002.

BAUMOL, W. J. e BOWEN, W. G. Performing arts: the economic dilemma. New York: The Twentieth Century Fund, 1966.

BILTON, C. e LEARY, R. What can managers do for creativity? Brokering creativity in the creative industries. International Journal of Cultural Policy, Vol. 8, n. 1, pp. 49-64, 2002.

BRITTO, J. Cooperação e aprendizado em arranjos produtivos locais: em busca de um referencial analítico. Nota técnica n. 4 do Projeto de Pesquisa Aprendizado, capacitação e cooperação em arranjos produtivos e inovativos locais de MPEs: implicações para políticas. 2004. Disponível em: <http://redesist.ie.ufrj.br/> Acesso: 05 Maio 2006.

BUSTAMANTE, E. Cultural industries in the digital age: some provisional conclusions. Media, Culture \& Society, 26(6), pp. 803-820. London: Sage Publications, 2004.

CASSIOLATO, J. E. e SZAPIRO, M. Uma caracterização de arranjos produtivos locais de micro e pequenas empresas. In: LASTRES, H. M. M., CASSIOLATO, J. E. e MACIEL, M. L. (orgs.). Pequena empresa: cooperação e desenvolvimento local. Rio de Janeiro: Relume Dumará / UFRJ, Instituto de Economia, 2003. Cap. 2. pp. 35-50.

CASTAÑER, X. e CAMPOS, L. The determinants of artistic innovation: bringing in the role of organizations. Journal of Cultural Economics, 26, pp. 29-52, 2002.

CAVAlCANTI, M. L. V. C. Carnaval carioca: dos bastidores ao desfile. Rio de Janeiro: Editora UFRJ / MinC/Funarte, 1995.

CAVES, R. E. Creative Industries: contracts between art and commerce. Cambridge: Harvard University Press, 2000.

. Contracts between arts and commerce. Journal of Economic Perspectives, 17 (2), pp. 73-83, spring 2003.

CUNNINGHAM, S. From cultural to creative industries: theory, industry, and policy implications. In: CULTURAL SITES, CULTURAL THEORY, CULTURAL POLICY: THE SECOND INTERNATIONAL CONFERENCE ON CULTURAL POLICY RESEARCH, Museum of New Zealand, Te Papa Tongarewa, Wellington, New Zealand, January 2002. 
DEPARTMENT OF CULTURE, MEDIA AND SPORT - DCMS. Creative industries mapping document. London, UK, 1998.

DOSI, G. Sources, procedures, and microeconomic effects of innovation. Journal of Economic Literature, 26, pp. 1120-1171, September, 1988.

EARP, F. S. (org.). Pão e circo: fronteiras e perspectives da economia do entretenimento. Rio de Janeiro: Palavra e Imagem, 2002.

FAJNZYLBER, F. Competitividad internacional: evolución y lecciones. Revista de la CEPAL, 36, 1988.

FAPERJ e COPPE/UFRJ. Economia da cultura: a força da indústria cultural no Rio de Janeiro. Epapers, Rio de Janeiro, 2002. 176p.

FERREIRA, F. O livro de ouro do carnaval brasileiro. Rio de Janeiro: Ediouro, 2004.

FILER, R. K. The "Starving Artist" - Myth or Reality? Earnings of Artists in the United States. Journal of Political Economy, 94 (1), pp. 56-75, 1986.

. Arts and academe: the effect of education on earnings of artists. Journal of Cultural Economics, 14 (2), pp. 15-38, 1990.

FLEW, T. Beyond Ad Hockery: Defining Creative Industries. In: SECOND INTERNATIONAL CONFERENCE ON CULTURAL POLICY RESEARCH, Wellington, New Zealand, 2002.

GETINO, O. Las industrias culturales y el mercosur. Revista Los Oficios Terrestres, n. 2, Argentina: Universidad Nacional de La Plata, 2001.

GIL, G. Conferência do Ministro da Cultura na Financiadora de Estudos e Projetos (Finep), Rio de Janeiro. 29/09/2004. Disponível em: <http://www.cultura.gov.br/corpo.php>. Acesso: 15 outubro 2004.

HOLLANDA, H. B. Considerações sobre o conceito de cultura. In: FAPERJ e COPPE/UFRJ. Economia da cultura: a força da indústria cultural no Rio de Janeiro. E-papers, Rio de Janeiro, 2002. pp. 25-32.

HOSKINS, C.; McFADYEN, S. e FINN, A. The environment in which cultural industries operate and some implications. Canadian Journal of Communication, 19 (3), 1994. 
HOWELLS, J. Innovation \& Services: New Conceptual Frameworks. Manchester: Centre for Research on Innovation and Competition, the University of Manchester, 2000

INSTITUTO PEREIRA PASSOS E SECRETARIA ESPECIAL DE ASSUNTOS ESTRATÉGICOS. O Impacto do carnaval na economia carioca. Rio de Janeiro, 1999.

KRETSCHMER, M. et al. Music in electronic markets: an empirical study. New Media \& Society 3(4): pp. 417-441, 2001.

LARAIA, R. B. Cultura: um conceito antropológico. Rio de Janeiro: Jorge Zahar Ed, 2002.

LASTRES, H. M. M. e CASSIOLATO, J. E. Innovation systems and local productive arrangements: new strategies to promote the generation, acquisition and diffusion of knowledge. Innovation: Management, Policy and Practice, 7 (2), April 2005.

LEMOS, C. Inovação para arranjos e sistemas produtivos de MPME. In: LASTRES, H. M. M. et al. (orgs.). Interagir para competir: promoção de arranjos produtivos e inovativos no Brasil. Brasília: SEBRAE / FINEP / CNPq, 2002. Cap. 3. pp. 95-134.

LEMOS, C., MATOS, M., SCHATZ, P., PEREIRA, M., CASSIOLATO, J. E. e LASTRES, H. M. M. Cultura e desenvolvimento: o APL da música de Conservatória/RJ. RedeSist-IE/UFRJ, jan/2005. Disponível em: <www.sinal.redesist.ie.ufrj.br> Acesso: 04 dez 2005.

LESSA, C.; AGUINAGA, R. O carnaval carioca: uma reestimativa do emprego e renda relacionados ao espetáculo. In: EARP, F. S. (org.). Pão e circo: fronteiras e perspectives da economia do entretenimento. Rio de Janeiro: Palavra e Imagem, 2002.

LIGA INDEPENDENTE DAS ESCOLAS DE SAMBA DO RIO - LIESA. Cidade do Samba. Disponível em: < http://liesa.globo.com/2007/por/20cidadedosamba/ocupacao/ocupacao_principal.htm >. Acesso em 02 outubro 2007.

MALERBA, F.; ORSENIGO, L. Technological regimes and sectoral patterns of innovative activities. Industrial and Corporate Change, n. 1, 1997.

MATOS, M. Innovation and competitiveness in creative/cultural activities. Mimeo, 2006.

- O sistema produtivo e inovativo local do carnaval carioca. Dissertação de Mestrado. Universidade Federal Fluminense, Centro de Pós-graduação em Economia. Niterói, 2007. 143p.

MATOS, M. P. e LEMOS, C. Using the approach of local productive arrangements and systems for the analysis of creative industries in Brazil: the case of Conservatória. In: THIRD GLOBELICS 
CONFERENCE: Innovation systems promoting economic growth, social cohesion and good governance. Tshwane (Pretoria), South Africa, 31 October - 4 November 2005. Available at: <http://www.globelics2005africa.org.za/papers/p0027/index.php>.

MEDINA, R. A indústria de espetáculos. In: FAPERJ e COPPE/UFRJ. Economia da cultura: a força da indústria cultural no Rio de Janeiro. Rio de Janeiro: E-papers, 2002. 176p.

MEIRELLES, D. S. E. O setor de serviços e os serviços de infra-estrutura econômica. Tese de doutorado em Economia. Rio de Janeiro: UFRJ, 2003.

MESQUITA, N. S. C. Inserção das micro e pequenas empresas na cadeia produtiva da economia do carnaval. Projeto final para obtenção do grau de especialista em gestão do conhecimento e inteligência. Rio de Janeiro: COPPE/UFRJ, 2006.

MILES, I. Innovation in services. In: DODGSON, M.; ROTHWELL, R. (ed.). The handbook of industrial innovation. Cheltenham, UK: Edward Elgar, 1994.

Service innovation: a reconfiguration of innovation studies. Discussion paper. PREST, The University of Manchester, 2001.

NELSON, R. R.; WINTER, S. G. In search of useful theory of innovation. Research policy, 6 (1), pp. 36-76, 1977.

O'CONNOR, J. The definition of 'cultural industries'. Manchester Institute for Popular Culture, 1999. Available at: <www.mmu.ac.uk/h-ss/mipc/iciss/home2.html> access: 11 November 2005

OWEN, B.; WILDMAN, S. Video economics. Cambridge, MA: Harvard University Press, 1992.

PAVITT, K. Sectoral patterns of technical change: towards a taxonomy and a theory. Research Policy, 13 (6), pp. 343-373, December, 1984.

PEACOCK, A. Welfare Economics and Public Subsidies to the Arts. The Manchester School of Economic and Social Studies, 1969. Reprinted in TOWSE, R. (ed.). Cultural economics: the arts, the heritage and the media industries. Vol. 2. Cheltenham: Edward Elgar, 1997. pp. 501-513.

PEGADO, I. A. S. A evolução do carnaval carioca: a festa popular que virou produto. Belém: UFPA, 2005.

PRATT, A. C. Cultural industries and public policy an oxymoron?. International Journal of Cultural Policy, 11(1), 2005. 
PRESTES FILHO, L. C. (Coord.). Cadeia produtiva da economia do carnaval. Rio de Janeiro: Epapers, 2009. 272p.

REDESIST - Rede de Pesquisa em Sistemas e Arranjos Produtivos e Inovativos Locais. Glossário de Arranjos e Sistemas Produtivos e Inovativos Locais. Rio de Janeiro: RedeSist-IE/UFRJ, 2005. Disponível em: <www.sinal.redesist.ie.ufrj.br> Acesso: 20 Dez 2005.

ROBBINS, L. Politics and economics: papers in political economy. London: Macmillan, 1963.

SECRETARIA DE ESTADO DE TRABALHO DO ESTADO DO RIO DE JANEIRO. Indústria do carnaval no Rio de Janeiro. Rio de Janeiro, 2000.

SCITOVSKY, T. Arts in the affluent society: what's wrong with the arts is what's wrong with society. The American Economic Review, 62 (1/2), pp. 62-69, 1972.

SUNDBO, J. Management of innovation in services. The Service Industries Journal, vol. 17, n. 3, pp. 432-455, 1997.

SUNDBO, J.; GALLOUJ, F. Innovation in Services. SI4S Synthesis Papers S, n. 2, 1998.

SUZIGAN, W., GARCIA, R. e FURTADO, J. Governança de sistemas produtivos locais de micro, pequenas e médias empresas. In: LASTRES, H. M. M., CASSIOLATO, J. E. e MACIEL, M. L. (org.) Pequena empresa: cooperação e desenvolvimento local. Rio de Janeiro: Relume Dumará / UFRJ, Instituto de Economia, 2003. Cap. 4 (pp. 67-84).

TOWSE, R. (ed.). Cultural economics: the arts, the heritage and the media industries. London: Edward Elgar, 1997.

THROSBY, D. The production and consumption of the arts: a view of cultural economics. Journal of Economic Literature, 32 (1), pp. 1-29, March, 1994.

THROSBY, D. Cultural capital. Journal of Cultural Economics, 23 (1-2), pp. 3-12, 1999. Economics and Culture. New York: Cambridge University Press, 2001.

. Determining the value of cultural goods: how much (or how little) does contingent valuation tell us?. Journal of Cultural Economics, 27, pp. 275-285, 2003.

TINHORÃO, J. R. História social da música popular brasileira. São Paulo: Ed. 34, 1998. 
UNESCO. Study on International Flows of Cultural Goods, 1980-98. Paris: UNESCO, 2000. 